\title{
Impact on ZVS Operation by Splitting Inductance to Both Sides of Transformer for 1- MHz GaN Based DAB Converter
}

\author{
Xiao, Yudi; Zhang, Zhe; Andersen, Michael A. E.; Sun, Kai
}

Published in:

IEEE Transactions on Power Electronics

Link to article, DOI:

10.1109/TPEL.2020.2988638

Publication date:

2020

Document Version

Peer reviewed version

Link back to DTU Orbit

Citation (APA):

Xiao, Y., Zhang, Z., Andersen, M. A. E., \& Sun, K. (2020). Impact on ZVS Operation by Splitting Inductance to Both Sides of Transformer for 1-MHz GaN Based DAB Converter. IEEE Transactions on Power Electronics, 35(11), 11988 - 12002. https://doi.org/10.1109/TPEL.2020.2988638

\section{General rights}

Copyright and moral rights for the publications made accessible in the public portal are retained by the authors and/or other copyright owners and it is a condition of accessing publications that users recognise and abide by the legal requirements associated with these rights.

- Users may download and print one copy of any publication from the public portal for the purpose of private study or research.

- You may not further distribute the material or use it for any profit-making activity or commercial gain

- You may freely distribute the URL identifying the publication in the public portal 


\title{
Impact on ZVS Operation by Splitting Inductance to Both Sides of Transformer for 1-MHz GaN Based DAB Converter
}

\author{
Yudi Xiao, Student Member, IEEE, Zhe Zhang, Senior Member, IEEE, and Michael A. E. Andersen, Member, IEEE \\ Kai Sun, Senior Member, IEEE
}

\begin{abstract}
Zero-voltage-switching (ZVS) of dual active bridge (DAB) converter and its range extension have been studied intensively. However, this paper proves that the external inductance location, i.e. placing on which side of the transformer, does affect the ZVS operation due to transformers' parasitic capacitances, in particular at a high switching frequency of higher than 1 MHz. Thus, this paper, for the first time, gives the mathematical model of the resonant transition during the dead time and thereby analyzes partial hard switching under different modulation schemes with consideration of transformer's parasitic capacitances. From the analysis of ZVS operation, the solution of splitting the interfacing inductance and placing them on both sides of the transformer is proposed and its associated methodology of selecting these inductances is introduced. It extends the ZVS for all the switching devices, therefore, enhance the efficiency or move losses away from the critical semiconductor devices. Finally, the theoretical analysis is verified by the experimental results from a $1 \mathrm{MHz}$ Gallium Nitride (GaN) based DAB converter prototype.
\end{abstract}

Keywords-dual active bridge, dc-dc converter, GaN, high frequency, parasitic capacitance, soft switching

\section{INTRODUCTION}

The Dual Active Bridge (DAB) converter, as shown in Fig. 1, was proposed in [1], and has attractive features in terms of low component stress, capability of bidirectional power flow, buckboost operation, large power capacity, ease of realizing softswitching, and modular and symmetrical structure [2][3]. In the last decade, much research of the DAB converter focuses on characterizing its zero-voltage-switching (ZVS) operation. Typically, when $V_{1}=N \cdot V_{2}$ ( $V_{1}$ and $V_{2}$ are the bus voltage, and $N$ is the transformer turn ratio, as denoted in Fig. 1), the ac current has trapezoidal shape and ZVS operation can be ensured over an entire load range. In [4]-[6], the ZVS conditions of the DAB converter were analyzed. However, the speed of charging switch junction capacitance was not studied. In [7], the resonant transition during the dead time of the DAB converter was characterized in time domain with consideration of its operation

Manuscript received, 9 Aug. 2019; accepted 3 Apr. 2020. This work was supported by Innovation Fund Denmark (IFD), EPIMES project 5185-00005B (Corresponding author: Zhe Zhang)

Yudi Xiao, Zhe Zhang and Michael A. E. Andersen are with the Department of Electrical Engineering, Technical University of Denmark, Kgs. Lyngby, Denmark, 2800. (Email: yudxiao@elektro.dtu.dk; zz@elektro.dtu.dk and ma@elektro.dtu.dk).

Kai Sun is with the Department of Electrical Engineering, Tsinghua University, Beijing, China, 100084. (Email: sun-kai@mail.tsinghua.edu.cn).

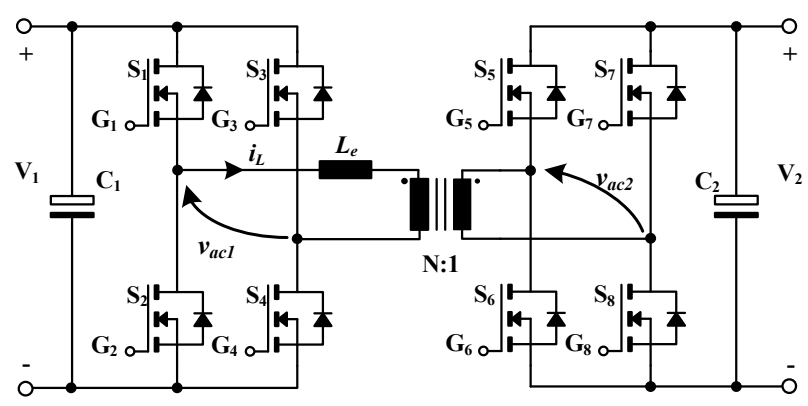

Fig. 1. Topology of the DAB converter.

modes. In [8], the ZVS conditions were studied with the criteria that the energy stored in the inductor is larger than the demanded energy of fully charging and discharging power switches' junction capacitance. Since the junction capacitance is both nonlinear and voltage-dependent, the voltage-averaged junction capacitance was used to obtain a more accurate calculation. In recent years, high frequency converters (switching frequency $\geq 1$ $\mathrm{MHz}$ ) with wide bandgap devices have attract more attention [9]-[11]. A Gallium Nitride (GaN)-based DAB converter was characterized by analyzing the resonant transition in time domain as well as considering the nonlinearity of $\mathrm{GaN}$ transistors' junction capacitance. In [13] and [14], the ZVS performance of a $1 \mathrm{MHz} \mathrm{DAB}$ converter was investigated. In [15], the resonant transition of ZVS operation was characterized in frequency domain by using harmonic decomposition of the DAB converter's switching-node waveforms. This method is not affected by a sequence change in the modulation pattern and thereby reduces the analysis complexity. In [14] and [15], the transformer's magnetizing inductance was considered in characterizing the resonant transition. With the above characterization methods, the ZVS range of the DAB converter with single-phase-shift-modulation (SPSM), where a phase shift is added between the two full bridges (FBs) to control the power flow, was found to be narrow [3]; however, the ZVS range is able to be extended by using advanced modulation strategies. In [16], the double-phase-shift-modulation (DPSM) was proposed. In comparison of SPSM, the FB at the high voltage side was modulated to generate a three-level voltage, and thereby DPSM can shape the inductor current to fulfill the conditions for ZVS even at light load with an additional degree of freedom, i.e. the duty ratio of the three-level PWM voltage. In [17], both of the FBs were modulated to generate three-level voltages, and the phase shift between them was used to control the power flow, 


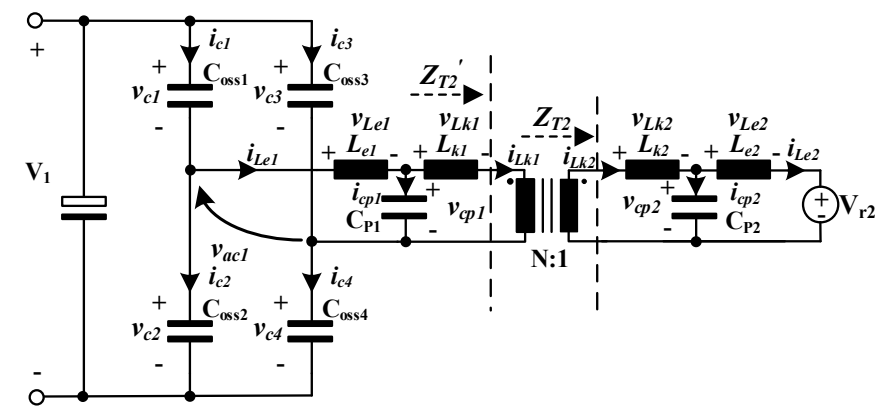

Fig. 2. Equivalent circuit of the DAB converter at resonant transition.

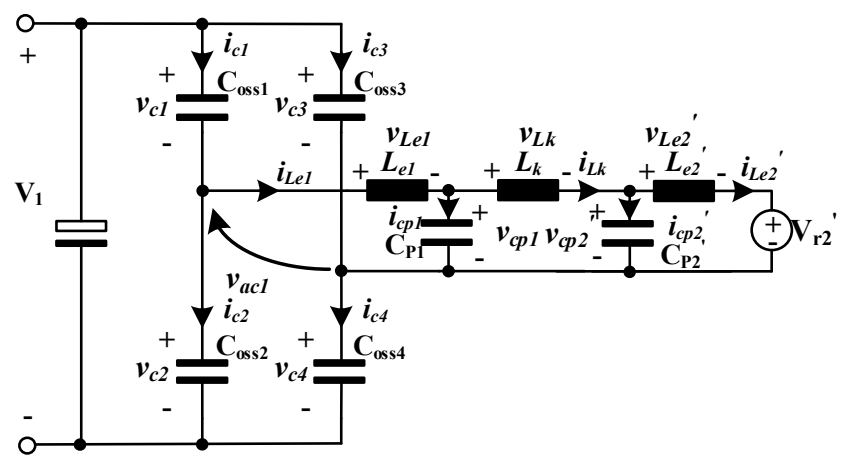

Fig. 3. Simplified equivalent circuit of the DAB converter during resonant transition.

while the duty ratio helped extend the ZVS range. In [18] and [19], the triple-phase-shift-modulation (TPSM) was proposed.

The FBs were modulated to generate phase shifted three-level PWM voltages with different duty ratios. Compared to the methods in [16] and [17], one more degree of freedom, i.e. the duty ratio of the other FB was used to extend ZVS regions, which were further studied in [20] under various load conditions.

In the literature of the DAB converters, the resonant transition during the dead time was characterized without considering transformer's parasitic capacitances. Given that and at the same time, assuming magnetizing inductance is large enough, the ac inductor location i.e. to which side of the transformer the inductor $L_{e}$, as illustrated in Fig. 1 is connected, does not affect the resonant transition. Thus, it has no impacts on ZVS operation of the DAB converter as long as its equivalent inductance is the same. As reported in [21], the transformer parasitic capacitance, in fact, can cause current resonance and finally worsen soft switching under SPSM. The impacts of transformer parasitic capacitances are analyzed by modelling the impedance of the ac link. Based on the analysis in frequency domain, an approach of distributing the external inductance on both sides of the transformer is proposed in order to mitigate the current resonance, which also means the placement of ac inductor does affect the ZVS performance. However, no equations are derived to describe how exactly this current resonance will change the switching behavior.

Therefore, this paper characterizes the impacts of transformer parasitic capacitance over ZVS operation of the DAB converters under SPSM, DPSM and TPSM in time domain. A mathematical model is derived to calculate the transition speed of the switching behavior, which also indicates the ZVS operation region. Then, it is proved experimentally that the location of the external inductance does affect ZVS of the DAB converter due to parasitic capacitances of a real transformer. Moreover, this issue becomes more critical in high frequency $(\geq 1 \mathrm{MHz}) \mathrm{DAB}$ converters equipped with Gallium Nitride (GaN) power transistors because of their smaller output capacitances (dozens to hundreds pico-farad only), which are comparable to transformer parasitic capacitances. In order to ensure ZVS on both the FBs, first, the external inductances need to be split and placed on both sides of the transformer; second, a certain amount of external inductance must be ensured on each side of the transformer, and the corresponding analysis and design is given in this paper.

This paper is organized as follows. After this introduction, Section II derives the mathematical model of the resonant transition with considering transformer parasitic capacitances. Section III compares the derived mathematical model with simulations. Section IV provides the method of using two external inductors to cancel out the influences from the transformer parasitic capacitances, and discusses the inductance selection. Section V presents the experimental results from a 1 $\mathrm{MHz}$ GaN-based DAB prototype. Finally, Section VI gives the conclusion.

\section{MAthematical Model of THE Resonant TRANSition}

\section{A. Equivalent Circuit of the Resonant Transition}

During the dead time of the FB connected to $V_{1}$, the equivalent circuit of the DAB converter is given in Fig. 2. $C_{o s s} 1-C_{o s s}$ represent the switch output capacitances and are assumed the same as $C_{o s s} . L_{e 1}$ and $L_{e 2}$ are the external inductance, $L_{k 1}$ and $L_{k 2}$ are the transformer leakage inductances, $C_{p 1}$ and $C_{p 2}$ are the parasitic capacitances of the windings on each side of the ac link, respectively.

As addressed in [22] and [23], the phase-drift phenomenon may happen when the lagging FB starts commutation during the dead time of the leading FB and finishes commutation before the leading FB. As a result, during the dead time of the FB connected to $V_{1}$, an all-inclusive analysis of the resonant transition will treat the $\mathrm{FB}$ connected to $V_{2}$ as either a bridge composed of four capacitors or a dc voltage source with possible values of $V_{2},-V_{2}$ and 0 . However, it turns out that such allinclusive analysis is very complicated. In [24], an so-called 'energy deadband' was found, in which the DAB converter's power is uncontrollable. In order to avoid such 'energy deadband', the two FBs must not commutate in dead time simultaneously. Therefore, considering both simplicity and no energy deadband, in this paper, we assume the lagging FB always starts commutation after the leading FB's commutation when derive the mathematical model of the resonant transition and carry out the model-based analysis. Then, the FB connected to $V_{2}$ is simplified as a voltage source $V_{r 2}$, and it has voltage of $V_{2},-V_{2}$ or 0 , depending on the operation modes of the DAB converter in different modulation schemes.

During the dead time of the FB connected to $V_{1}, Z_{T 2}$ and $Z_{T 2}$, denoted in Fig.1, are calculated by (1) and (2), respectively. 


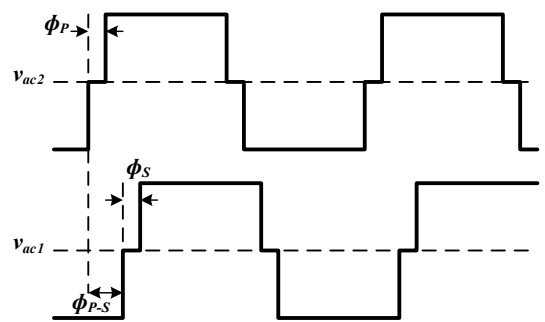

Fig. 4. Typical steady-state voltage waveforms of the DAB converter.

$$
\begin{gathered}
Z_{T 2}=j \omega L_{k 2}+\frac{\frac{1}{j \omega C_{P 2}} j \omega L_{e 2}}{\frac{1}{j \omega C_{P 2}}+j \omega L_{e 2}} . \\
Z_{T 2}^{\prime}=N^{2} Z_{T 2}=j \omega N^{2} L_{k 2}+N^{2} \frac{\frac{1}{j \omega C_{P 2}} j \omega L_{e 2}}{\frac{1}{j \omega C_{P 2}}+j \omega L_{e 2}} .
\end{gathered}
$$

Then (2) is rewritten as

$$
Z_{T 2}^{\prime}=j \omega N^{2} L_{k 2}+\frac{\frac{1}{j \omega \frac{C_{P 2}}{N^{2}}} j \omega N^{2} L_{e 2}}{\frac{1}{j \omega \frac{C_{P 2}}{N^{2}}}+j \omega N^{2} L_{e 2}} .
$$

Based on (3), the equivalent circuit parameters on the secondary side of the transformer in Fig. 2 can be referred to the primary side as shown in Fig. 3, where

$$
V_{r 2}^{\prime}=N V_{r 2}, L_{e 2}^{\prime}=N^{2} L_{e 2}, C_{P 2}^{\prime}=\frac{C_{P 2}}{N^{2}}, L_{k}=L_{k 1}+N^{2} L_{k 2}
$$

\section{B. Label the Switching Patterns}

As introduced in Section I, $v_{a c 1}$ can be either a two-level or a three-level voltage, depending on the adopted modulation strategy. Even though there are many combinations of two-level or three-level $v_{a c 1}$ and $V_{r 2}$ voltage of $V_{2},-V_{2}$ or 0 , the analysis can be simplified by using defined switching patterns. Note that the switching patterns defined here do not apply to hardswitching transitions.

Typical waveforms of $v_{a c 1}$ and $v_{a c 2}$ are given in Fig. 4 and both of them are three-level voltages. $v_{a c 1}$ is modulated to have an inner phase shift $\phi_{S}$ and lagged behind $v_{a c 2}$ by a phase shift $\phi_{P-S}$. $v_{a c 2}$ is modulated to have an inner phase shift $\phi_{P}$. This typical waveform can be used to describe the operation of DAB converters with SPSM, DPSM and TPSM by assigning different values to $\phi_{P}, \phi_{S}$ and $\phi_{P-S}$. Definitions of the switching-patterns are given in Table I, and the relationships of $\phi_{P}, \phi_{S}$ and $\phi_{P-S}$ under different modulation strategies are summarized in Table II. Four switching patterns, i.e. Switching-Pattern \#1 \#4, are defined, so that investigating the impacts of ac inductor placement on the DAB converters with SPSM, DPSM and TPSM can be simplified as characterizing Switching-Pattern \#1 \#4.

\section{Equations of the Resonant Transition}

The aims of this paper are: 1) to raise the issue, which is the impact of ac inductor placement on ZVS operation of the DAB converter, and 2) to provide a solution, i.e. put at least the minimum amount of external inductance on each side of the ac link. Deriving equations of all of the four switching patterns will be the most preferred way of reaching these two aims. However, in Table II, one can conclude that one of the FBs will be in hard
TABLE I. DEFINITIONS OF SWITCHING PATTERnS

\begin{tabular}{|c|c|c|c|}
\hline $\begin{array}{l}\text { Modulation } \\
\text { Strategy }\end{array}$ & $\begin{array}{l}\text { Relationship of } \\
\text { phase shift angle }\end{array}$ & $\begin{array}{c}\text { Switching } \\
\text { pattern of } v_{a c 1}\end{array}$ & $\begin{array}{c}\text { Switching } \\
\text { pattern of } v_{a c 2}\end{array}$ \\
\hline SPSM & $\phi_{P}=\phi_{\mathrm{S}}=0$ & $\begin{array}{l}\text { Switching- } \\
\text { Pattern \#1 }\end{array}$ & $\begin{array}{l}\text { Switching- } \\
\text { Pattern \#1 }\end{array}$ \\
\hline $\begin{array}{l}\text { Modulation } \\
\text { in [13] }\end{array}$ & $\phi_{P}=0, \phi_{S} \neq 0$ & $\begin{array}{l}\text { Switching- } \\
\text { Pattern \#2 }\end{array}$ & $\begin{array}{l}\text { Switching- } \\
\text { Pattern \#1 }\end{array}$ \\
\hline $\begin{array}{l}\text { Modulation } \\
\text { in [13] }\end{array}$ & $\phi_{S}=0, \phi_{P} \neq 0, \phi_{P}<\phi_{P-S}$ & $\begin{array}{l}\text { Switching- } \\
\text { Pattern \#1 }\end{array}$ & $\begin{array}{l}\text { Switching- } \\
\text { Pattern \#2 }\end{array}$ \\
\hline $\begin{array}{l}\text { Modulation } \\
\text { in [13] }\end{array}$ & $\phi_{S}=0, \phi_{P} \neq 0, \phi_{P}>\phi_{P-S}$ & $\begin{array}{l}\text { Switching- } \\
\text { Pattern \#3 }\end{array}$ & $\begin{array}{c}\text { Switching- } \\
\text { Pattern \#2+ } \\
\text { hard } \\
\text { switching }\end{array}$ \\
\hline DPSM & $\begin{array}{c}\phi_{P}=\phi_{S} \neq 0, \\
\phi_{P}<\phi_{P-S}\end{array}$ & $\begin{array}{l}\text { Switching- } \\
\text { Pattern \#2 }\end{array}$ & $\begin{array}{l}\text { Switching- } \\
\text { Pattern \#2 }\end{array}$ \\
\hline DPSM & $\begin{array}{c}\phi_{P}=\phi_{S} \neq 0, \\
\phi_{P}>\phi_{P-S}\end{array}$ & $\begin{array}{c}\text { Switching- } \\
\text { Pattern \#4+ } \\
\text { Switching- } \\
\text { Pattern \#2 } \\
\end{array}$ & $\begin{array}{c}\text { Switching- } \\
\text { Pattern } \# 2+ \\
\text { hard } \\
\text { switching }\end{array}$ \\
\hline TPSM & $\begin{array}{c}\phi_{P} \neq \phi_{S} \neq 0 \\
\phi_{P}<\phi_{P-S}\end{array}$ & $\begin{array}{l}\text { Switching- } \\
\text { Pattern \#2 }\end{array}$ & $\begin{array}{l}\text { Switching- } \\
\text { Pattern \#2 }\end{array}$ \\
\hline TPSM & $\begin{array}{c}\phi_{P} \neq \phi_{S} \neq 0 \\
\phi_{P-S}<\phi_{P}<\phi_{P-S}+\phi_{S}\end{array}$ & $\begin{array}{c}\text { Switching- } \\
\text { Pattern \#4+ } \\
\text { Switching- } \\
\text { Pattern \#2 } \\
\end{array}$ & $\begin{array}{c}\text { Switching- } \\
\text { Pattern \#2+ } \\
\text { hard } \\
\text { switching }\end{array}$ \\
\hline TPSM & $\begin{array}{c}\phi_{P} \neq \phi_{S} \neq 0 \\
\phi_{P}>\phi_{P-S}+\phi_{S}\end{array}$ & $\begin{array}{l}\text { Switching- } \\
\text { Pattern \#4 }\end{array}$ & $\begin{array}{c}\text { Switching- } \\
\text { Pattern \#2+ } \\
\text { hard } \\
\text { switching }\end{array}$ \\
\hline
\end{tabular}

$\left.\begin{array}{|c|c|c|}\hline \begin{array}{c}\text { Switching } \\ \text { pattern } \\ \text { number }\end{array} & \text { Definition } \\ \hline \multirow{8}{*}{\# 1} & \begin{array}{c}\text { During resonant transition, } \\ \text { (i) the switching node } \\ \text { voltage of the FB in } \\ \text { resonant transition reverses } \\ \text { polarity; (ii) the switching } \\ \text { node voltage of the other } \\ \text { FB is of a non-zero value. }\end{array} \\ \begin{array}{c}\text { During resonant transition, } \\ \text { (i) the switching node } \\ \text { voltage of the FB in } \\ \text { resonant transition changes } \\ \text { from a non-zero value to } \\ \text { zero or from zero to a non- } \\ \text { zero value; (ii) the } \\ \text { switching node voltage of } \\ \text { the other FB is of a non- } \\ \text { zero value }\end{array} \\ \begin{array}{c}\text { During resonant transition, } \\ \text { (i) the switching node } \\ \text { voltage of the FB in } \\ \text { resonant transition reverses } \\ \text { polarity; (ii) the switching } \\ \text { node voltage of the other } \\ \text { FB is zero. }\end{array} \\ \begin{array}{c}\text { During resonant transition, } \\ \text { (i) the switching node } \\ \text { voltage of the FB in } \\ \text { resonant transition changes } \\ \text { from a non-zero value to } \\ \text { zero or from zero to a non- } \\ \text { zero value; (ii) the } \\ \text { switching node voltage of } \\ \text { the other FB is zero. }\end{array} \\ \hline \# 3\end{array}\right)$

TABle II. Modulation StRategies AND the SWitching Patterns INVOLVED 
switching when either Switching-Pattern \#3 or SwitchingPattern \#4 is used, and then the mathematical analysis can simplified as described below.

Due to hard switching, Switching-Pattern \#3 and SwitchingPattern \#4 cannot be used in practice, so that deriving equations for Switching-Pattern \#3 and Switching-Pattern \#4 are omitted here and the mathematical work focuses on Switching-Pattern $\# 1$ and Switching-Pattern \#2. Moreover, only the equations of Switching-Pattern \#1 are derived in order to implement theoretical analysis. Nevertheless, experiments under Switching-Pattern \#2 are completed to investigate the impact of ac inductor placement on the DAB converter in this mode.

In addition, the derived equations can be directly used for analyzing Switching-Pattern \#3 by changing the initial condition of $V_{r 2}$ ' to 0 , as stated in Section IV-C. On the other hand, the derived equations can also be modified to characterize Switching-Pattern \#2 and Switching-Pattern \#4 by changing the initial voltage across $C_{o s s}-C_{o s s}$ at the beginning of the resonant transition. This modification does not change the order of the final differential equation. Therefore, the numerical solver chosen in this paper can be used to solve newly derived models with high accuracy.

From Fig. 3, according to Faraday's law, Kirchhoff's voltage law and Kirchhoff's current law, the following equations can be given.

$$
\begin{gathered}
v_{L e 2}^{\prime}(t)=L_{e 2}^{\prime} \frac{d i_{L e 2}^{\prime}(t)}{d t} \\
v_{c p 2}^{\prime}(t)=v_{L e 2}^{\prime}(t)+V_{r 2}^{\prime} \\
i_{c p 2}^{\prime}(t)=C_{P 2}^{\prime} \frac{d v_{c p 2}^{\prime}(t)}{d t} \\
i_{L k}(t)=i_{c p 2}^{\prime}(t)+i_{L e 2}^{\prime}(t) \\
v_{L k}(t)=L_{k} \frac{d i_{L k}(t)}{d t} \\
v_{c p 1}(t)=v_{L k}(t)+v_{c p 2}^{\prime}(t) \\
i_{c p 1}(t)=C_{P 1} \frac{d v_{c p 1}(t)}{d t} \\
i_{L e 1}(t)=i_{c p 1}(t)+i_{L k}(t) \\
v_{L e 1}(t)=L_{e 1} \frac{d i_{L e 1}(t)}{d t} \\
v_{a c 1}(t)=v_{L e 1}(t)+v_{c p 1}(t) \\
i_{c 4}(t)=C_{o s s} \frac{d v_{c 4}(t)}{d t}=C_{o s s} \frac{d\left(\frac{V_{1}-v_{a c 1}(t)}{2}\right)}{d t} \\
i_{L e 1}(t)=i_{c 4}(t)-i_{c 3}(t) \\
i_{c 3}(t)=-i_{c 4}(t) \\
i_{L e 1}(t)=2 i_{c 4}(t)=-C_{o s s} \frac{d v_{a c 1}(t)}{d t}
\end{gathered}
$$

Substituting (5)-(11) into (12), substituting (5)-(17) into (18), and equaling (12) and (18) obtain the following differential equation.

$$
\begin{aligned}
& -C_{o s s}\left[L_{e 1} C_{P 1} L_{k} C_{P 2}^{\prime} L_{e 2}^{\prime} \frac{d^{6} i_{L e 2}^{\prime}(t)}{d t^{6}}+\left(L_{e 1} C_{P 1} L_{k}+L_{e 1} C_{P 1} L_{e 2}^{\prime}\right.\right. \\
+ & \left.\left.L_{e 1} C_{P 2}^{\prime} L_{e 2}^{\prime}+L_{k} C_{P 2}^{\prime} L_{e 2}^{\prime}\right) \frac{d^{4} i_{L e 2}^{\prime}(t)}{d t^{4}}+\left(L_{e 1}+L_{k}+L_{e 2}^{\prime}\right) \frac{d^{2} i_{L e 2}^{\prime}(t)}{d t^{2}}\right] \\
= & C_{P 1} L_{k} C_{P 2}^{\prime} L_{e 2}^{\prime} \frac{d^{4} i_{L 2}^{\prime}(t)}{d t^{4}}+\left(C_{P 1} L_{k}+C_{P 1} L_{e 2}^{\prime}+C_{P 2}^{\prime} L_{e 2}^{\prime}\right) \frac{d^{2} i_{L e e}^{\prime}(t)}{d t^{2}}+i_{L e 2}^{\prime}(t)
\end{aligned}
$$

The solution of $i_{\text {Le2 }}(t)$ can be obtained by solving (19) numerically. Since all of the circuit states, i.e. $v_{c p 2}(t), i_{c p 2}(t)$, $i_{L k}(t), v_{c p 1}(t), i_{c p 1}(t), i_{L e 1}(t), v_{a c 1}(t)$, etc., are functions of $i_{L e 2}(t)$, the resonant transition is numerically solved in time domain.

TABL III. PARAMETERS USED IN CALCULATIONS AND SIMULATIONS
\begin{tabular}{|c|c||c|c|}
\hline$C_{\text {oss }}$ & $17 \mathrm{pF}$ & $N$ & 4 \\
\hline$C_{p 1}$ & $18 \mathrm{pF}$ & $L_{e 1}$ & $1 \mu \mathrm{H}-19 \mu \mathrm{H}$ \\
\hline$C_{p 2}$ & $285 \mathrm{pF}$ & $L_{e 2}$ & $\left(20 \mu \mathrm{H}-L_{e l}\right) / N^{2}$ \\
\hline$V_{1}$ & $200 \mathrm{~V}$ & $L_{k 1}$ & $300 \mathrm{nH}$ \\
\hline$V_{2}$ & $50 \mathrm{~V}$ & $L_{k 2}$ & $20 \mathrm{nH}$ \\
\hline
\end{tabular}

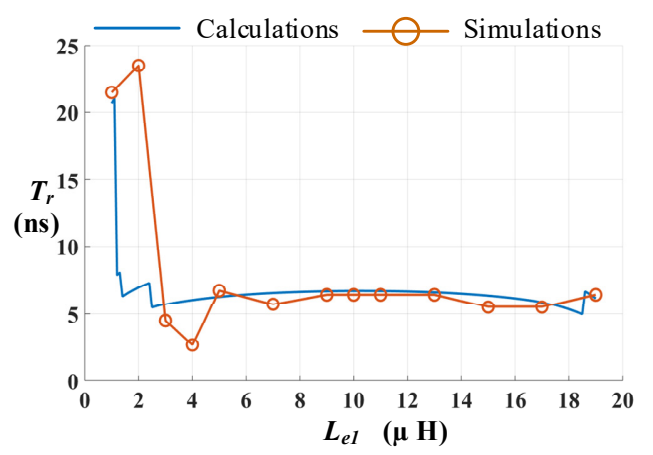

Fig. 5. Calculated and simulated $T_{r}$ vs. $L_{e 1}$.

TABLE IV. $\quad i_{L e 2}(0)$ OBTAINED FROM SIMULATIONS

\begin{tabular}{|c|c|c|c|}
\hline$V_{2}$ & $50 \mathrm{~V}\left(V_{1}=N V_{2}\right)$ & $40 \mathrm{~V}\left(V_{1}>N V_{2}\right)$ & $60 \mathrm{~V}\left(V_{1}<N V_{2}\right)$ \\
\hline$i_{L e 2}(0) @ V_{\mathrm{r} 2}=V_{2}(\mathrm{~A})$ & -1.4 & -1.3 & -0.9 \\
\hline$i_{L e 2}(0) @ V_{\mathrm{r} 2}=0(\mathrm{~A})$ & -0.7 & -1.0 & -0.4 \\
\hline
\end{tabular}

\section{Simulations}

Equation (19) is firstly verified by simulations of the DAB converter with SPSM under $V_{1}=N \cdot V_{2}$ and a $V_{1}$-to- $V_{2}$ phase shift angle of $-6 \pi / 25$, which is also the phase shift angle used in the experiments. In MATLAB with PLECS Blockset and (19) is numerically solved with ODE-solver-'ode45'. The parameters used in calculations and simulations are given in Table III. These parameters are extracted from the constructed experimental prototype. In the calculations, $i_{L e 2}(0)$ is set to be -1.4 , which is obtained from simulations done in PLECS using parameters in Table III. Note that $i_{\text {Le2 }}(0)$ could also be calculated by the equation given in (20), where $f_{s}$ is switching frequency. $i_{L e 2}(0)$ is set to be $\left.\left(V_{1}-V_{r 2}\right)^{\prime}\right) /\left(L_{e 1}+N^{2} L_{e 2}\right)$, while $\mathrm{d}^{2} i_{L e 2}(0) \sim \mathrm{d}^{5} i_{L e 2}(0)$ are set to be 0 because of the linear shape of the ac current before the dead time. With different $L_{e l}$, the calculated and simulated $T_{r}$, which is defined as the time duration of $v_{a c 1}(t)$ rising from $-200 \mathrm{~V}$ to $200 \mathrm{~V}$ with $V_{r 2}=50 \mathrm{~V}$, are shown in Fig. 5. $L_{e 2}$ is adjusted according to $L_{e l}$ in order to ensure the same power delivered by the DAB converter. Note that $T_{r}$ is the minimum dead time to achieve ZVS.

In Fig. 5, the calculations and the simulations show the same trend: when $L_{e 1}$ is small, e.g. $1 \mu \mathrm{H}$, which means that most of the external inductance is contributed by $L_{e 2}$, it takes approximately $20 \mathrm{~ns}$ for $v_{a c 1}(t)$ to rise from $-200 \mathrm{~V}$ to $200 \mathrm{~V}$. When $L_{e l}$ is increased to approximately $2 \mu \mathrm{H}$, which means that additional 1 $\mu \mathrm{H}$ is assigned to $L_{e l}$, it only takes approximately $5 \mathrm{~ns}$ for $v_{a c 1}(t)$ to rise from $-200 \mathrm{~V}$ to $200 \mathrm{~V}$. When $L_{e l}$ is increased further, the required time to achieve ZVS remains at around $5 \mathrm{~ns}$. The reason for this discontinuity of $T_{r}$ when increasing $L_{e 1}$ will be given in Section IV. There are differences between the calculations and the simulations, which are caused by the inherent errors of the numerical-solutions used. Since the simulations and calculations shows the same trend, and the calculated maximum $T_{r}$ and the calculated minimum $T_{r}$ matches the simulated ones, the derived 


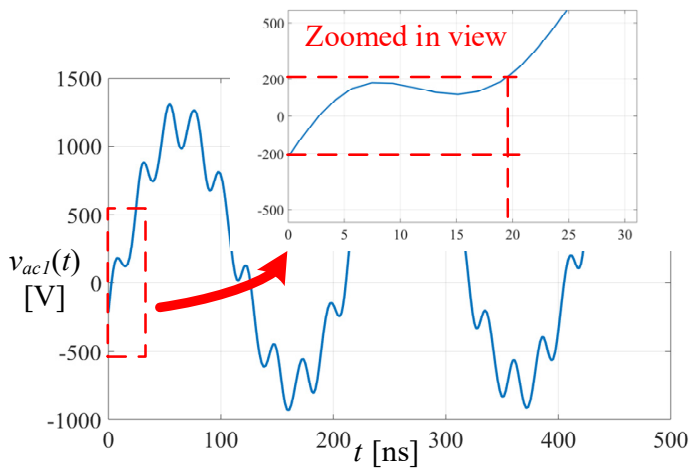

(a). Calculated $v_{a c l}(t)$ at $L_{e 1}=1 \mu \mathrm{H}$

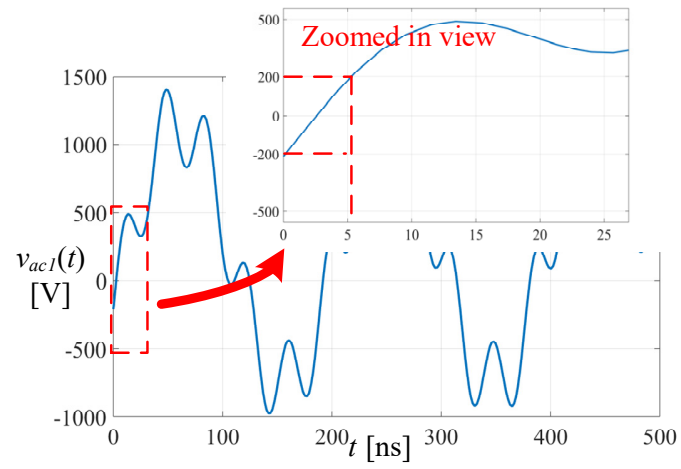

(b). Calculated $v_{a c l}(t)$ at $L_{e 1}=3 \mu \mathrm{H}$

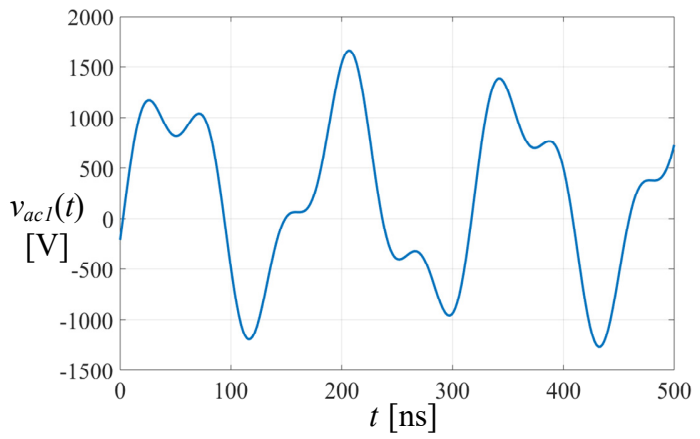

(c). Calculated $v_{a c l}(t)$ at $L_{e 1}=10 \mu \mathrm{H}$

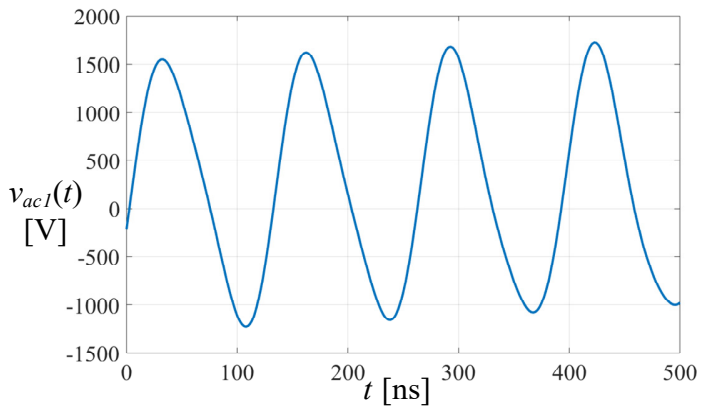

(d). Calculated $v_{a c l}(t)$ at $L_{e 1}=15 \mu \mathrm{H}$

Fig. 6. Calculated $v_{a c 1}(t)$ at different $L_{e 1}$.

mathematical model is adopted to carry out the analysis in Section IV.

$$
i_{L e 2}^{\prime}(0)=-\frac{\frac{\phi p-s}{\pi}\left(-2 N V_{2}\right)+V_{1}+N V_{2}}{4 N f_{S}\left(L_{e 1}+N^{2} L_{e 2}\right)}
$$

IV. ANALYSIS OF THE RESONANT TRANSITION AND ZVS

In this section, the resonant transition during the dead time of the DAB converter under $V_{1}=N \cdot V_{2}$ with $V_{r 2}=V_{2}$, i.e. SwitchingPattern \#1 with $V_{1}=N \cdot V_{2}$, is analyzed in detail. After this detailed analysis, the calculated $T_{r}$ vs. $L_{e 1}$ under $V_{1}=N \cdot V_{2}, V_{1}>N \cdot V_{2}$, $V_{1}<N \cdot V_{2}$ with $V_{r 2}$ equals to $V_{2}$ and 0 , i.e. Switching-Pattern \#1 and Switching-Pattern \#3 with $V_{1}=N \cdot V_{2}, V_{1}>N \cdot V_{2}, V_{1}<N \cdot V_{2}$, are directly given. Because the DAB converter's waveforms are symmetrical in every half-switching cycle, only the analysis in the positive half cycle is given. Since $T_{r}$ is the minimum dead time to achieve ZVS, the analysis of $T_{r}$ is critical to study the impacts of ac inductance placement.

\section{A. Influences of Transformer Parasitic Capacitances on $T_{r}$}

Assume that the resonance is not interrupted by the actions of the switches, and by using the parameters listed in Table III, the calculated waveforms of $v_{a c 1}(t)$ with $L_{e 1}$ of $1 \mu \mathrm{H}, 3 \mu \mathrm{H}, 10 \mu \mathrm{H}$ or $15 \mu \mathrm{H}$ are plotted in Fig. 6 , where $V_{1}=N \cdot V_{2}, V_{r 2}=V_{2}, i_{L e 2}{ }^{\prime}(0)=$ -1.4, $\mathrm{d}_{L e 2}{ }^{\prime}(0)=\left(V_{1}-V_{r 2}{ }^{\prime}\right) /\left(L_{e 1}+N^{2} L_{e 2}\right)$, and $\mathrm{d}^{2} i_{L e 2}{ }^{\prime}(0) \sim \mathrm{d}^{5} i_{L e 2}{ }^{\prime}(0)=0$.

The resulted $v_{a c 1}(t)$ is no longer pure sinusoidal, and therefore, $T_{r}$ or the minimum dead time for achieving ZVS calculated in [7] may cause errors. The expression of $v_{a c 1}(t)$ derived in [7] is given as (21), where definitions of $Z_{0}$ and $\omega_{0}$ are defined in (22) and (23). As shown in Fig. 6(a), the non-sinusoidal nature of $v_{a c 1}(t)$ requires the $T_{r}$ to be around $20 \mathrm{~ns}$, which is 3 times larger than the $4.9 \mathrm{~ns}$ calculated by the equations in [7], where $C_{p 1}$ and $C_{p 2}$ are neglected. Thus, if the dead time is set based on the equations in [7], the DAB converter will lose ZVS.

$$
\begin{gathered}
v_{a c 1}(t)=-N V_{2}-i_{L e 1}(0) Z_{0} \sin \left(\omega_{0} t\right)+\left(-V_{1}+N V_{2}\right) \cos \left(\omega_{0} t\right) \\
Z_{0}=\sqrt{\frac{L_{e}}{c_{o s s}}} \\
\omega_{0}=\frac{1}{Z_{0}}
\end{gathered}
$$

\section{B. Placing External Inductances to Shorten $T_{r}$}

The existence of $C_{p 1}$ and $C_{p 2}$ leads to a non-sinusoidal $v_{a c 1}(t)$, and it is possible to make $v_{a c 1}(t)$ quasi-sinusoidal by adjusting $L_{e 1}$. As shown in Fig. 6(b)-(d), if $L_{e l}$ increases, $v_{a c 1}(t)$ will become less non-sinusoidal. And with a quasi-sinusoidal $v_{a c 1}(t)$, $T_{r}$ can be reduced. With a reduced $T_{r}$, ZVS operation can be guaranteed even with a small dead time.

In Fig. 7, the influences of $L_{e 1}$ on $T_{r}$ under different $C_{p 1}$ are given, where $C_{p 2}$ is assigned to be $N^{2}$ times of $C_{p 1}$. As shown, when $L_{e 1}$ is small, $T_{r}$ increases when $C_{p 1}$ and $C_{p 2}$ are increased. In order to keep $T_{r}$ small even though $C_{p 1}$ and $C_{p 2}$ are increased, $L_{e 1}$ needs to be increased accordingly.

In Fig. 8, the influences of $L_{e 1}$ on $T_{r}$ under different $i_{L e 2}$ '(0) are given. Since $i_{L e 2}{ }^{\prime}(0)$ is related to the input/output power, i.e. the higher the input/output power, the larger the absolute value of $i_{L e 2}$ '(0), Fig. 8 actually indicates the influences of $L_{e 1}$ on $T_{r}$ under different power. As shown, when $L_{e 1}$ is small, $T_{r}$ increases when $i_{L e 2}$ '(0) is increased. In order to keep $T_{r}$ small even though $i_{L e 2}{ }^{\prime}(0)$ is increased, $L_{e 1}$ needs to be increased accordingly. The smallest $T_{r}$ under different $i_{L e 2}{ }^{\prime}(0)$ increases when $i_{L e 2}$ '(0) is increased.

Fig. 9 shows the realization of ZVS under different combinations of $L_{e 1}$ and dead time $T_{d}$. The combinations with which ZVS can be achieved are marked as grey area. Based on 


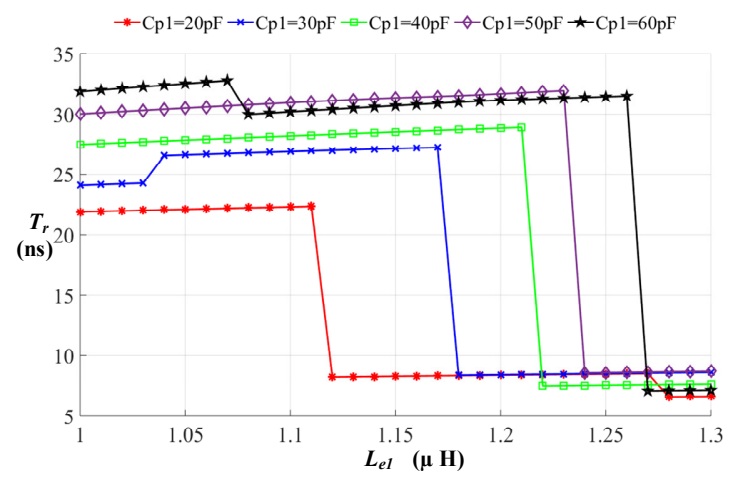

Fig. 7. Calculated $T_{r}$ vs. $L_{e 1}$ under different $C_{p 1}, C_{p 2}=N^{2} C_{p 1} @ i_{L e 2}{ }^{\prime}(0)=-1.4 \mathrm{~A}$.

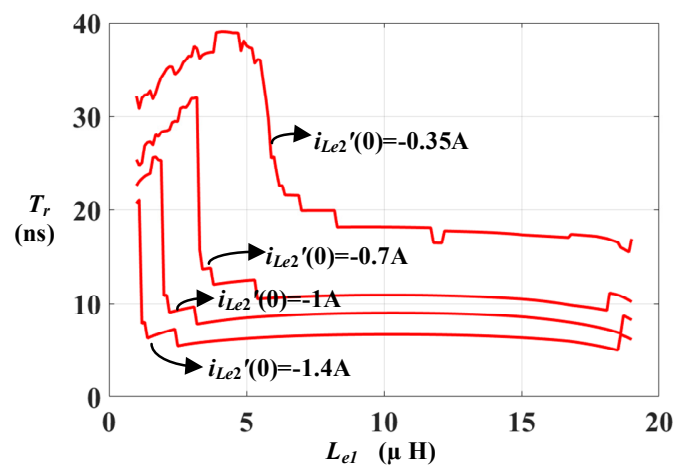

Fig. 8. Calculated $T_{r}$ vs. $L_{e 1}$ under different $i_{L e 2}{ }^{\prime}(0), @ C_{p 1}=18 \mathrm{pF}$.

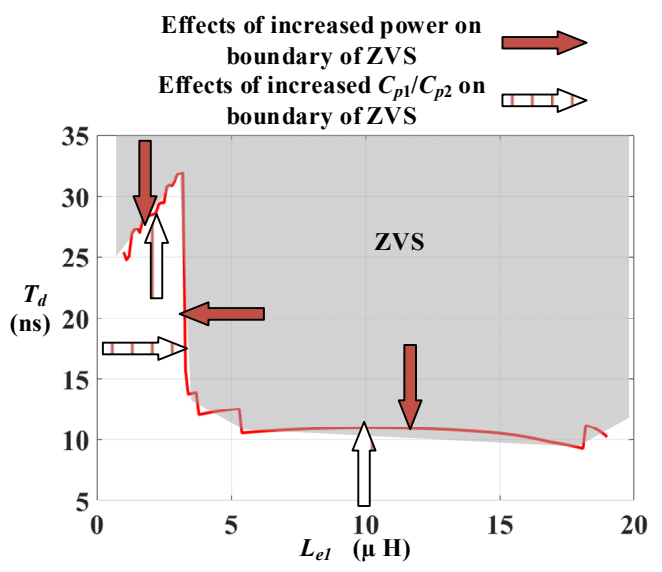

Fig. 9. Realization of ZVS, @ $i_{L e 2}{ }^{\prime}(0)=-1.4 \mathrm{~A}, C_{p 1}=18 \mathrm{pF}$.

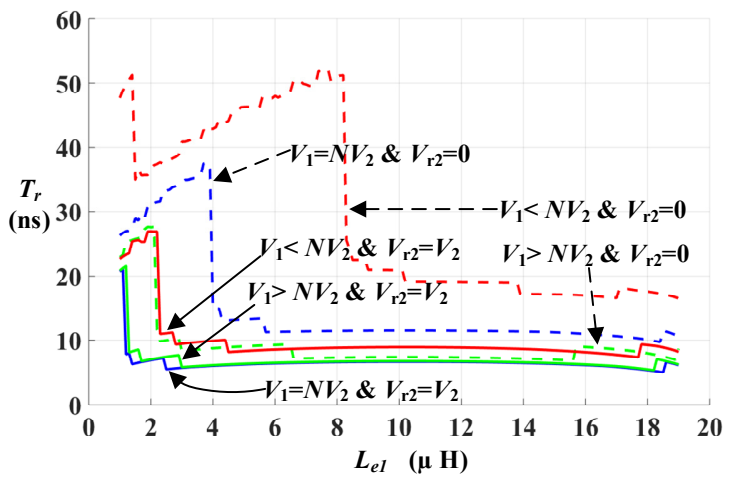

Fig. 10. Calculated $T_{r}$ vs. $L_{e 1}$ under $V_{1}=N \cdot V_{2}, V_{1}>N \cdot V_{2}, V_{1}<N \cdot V_{2} \& V_{r 2}=V_{2}$ and 0 analysis on Fig. 7 and 8, the influences of power and transformer parasitic capacitance on realization of ZVS is summarized in Fig. 9 as well. As shown, the ZVS area is enlarged when power is increased or transformer parasitic capacitance is decreased, and vice versa.

Fig. 6 also explains the discontinuity of $T_{r}$ in Figs. 5, 7 and 8. As shown in Fig. 6(a), the first wave crest of $v_{a c 1}(t)$ is smaller than $200 \mathrm{~V}$, which is the DC voltage connected to the FB. $v_{a c 1}(t)$ reaches $200 \mathrm{~V}$ after the first wave trough. As a result, $T_{r}$ must be larger than the time when $v_{a c 1}(t)$ is at the first wave trough. However, once the first wave crest of $v_{a c 1}(t)$ is increased to 200 $\mathrm{V}$ with increasing $L_{e 1}, T_{r}$ will be directly shorten to be the time when $v_{a c 1}(t)$ is at the first wave crest.

\section{C. $\quad T_{r}$ versus $L_{e l}$ Curves of Switching-Patterns \#1 and \#3}

The calculated $T_{r}$ versus $L_{e 1}$ curves with $V_{1}=N \cdot V_{2}, V_{1}>N \cdot V_{2}$, $V_{1}<N \cdot V_{2} \& V_{r 2}=V_{2}$ and 0 are given in Fig. 10. $i_{\text {Le2 }}$ ( $(0)$ used in the calculations is obtained from simulations done in PLECS and are given in Table IV. Note that $i_{L e 2}(0)$ could also be calculated by the equation given in (24) [25]. These simulations are based on parameters in Table III, except $V_{2}$, which is changed accordingly in order to make $V_{1}$ be either larger/smaller than or equal to $N V_{2}$. The $\phi_{P-S}$ used in simulations is $-6 \pi / 25$, and an additional inner phase shift angle $\phi_{P}$ of $8 \pi / 25$ is added to the FB connected to $V_{2}$ in $V_{r 2}=0$ cases.

$$
i_{L e 2}^{\prime}(0)=-\frac{V_{1}\left(1-\frac{\phi p}{\pi}\right)+N V_{2} \frac{2|\phi p-s|+\phi_{s}-\pi}{\pi}}{2 f_{S}\left(L_{e 1}+N^{2} L_{e 2}\right)}
$$

As shown in Fig. 10, in all of the considered cases where $V_{1}=N \cdot V_{2}, V_{1}>N \cdot V_{2}, V_{1}<N \cdot V_{2} \& V_{r 2}=V_{2}$ and $0, T_{r}$ decreases sharply at certain $L_{e 1}$. Therefore, the impact of ac inductor placement on the resonant transition does exist. Moreover, the following patterns and the corresponding characterizations can be found:

- The solid lines are not overlapped with each other, neither do the dashed lines. Therefore, the relationship between $V_{1}$ and $\mathrm{NV}_{2}$ affects the resonant transition.

- All of the dashed lines are on the up-right side of the solid lines with the same color. Therefore, with the same relationship between $V_{1}$ and $\left.N V_{2}, 1\right) T_{r}$ under $V_{r 2}=0$ is always larger than $T_{r}$ under $\left.V_{r 2}=V_{2} ; 2\right) L_{e 1}$ with which $T_{r}$ starting to drastically decrease under $V_{r 2}=0$ is larger than that under $V_{r 2}=V_{2}$.

- As shown in the $T_{r}$ vs. $L_{e 1}$ curve under $V_{1}<N \cdot V_{2} \& V_{r 2}=0, T_{r}$ drops drastically twice, i.e. $T_{r}$ firstly steps down from $50 \mathrm{~ns}$ to $35 \mathrm{~ns}$ at $L_{e 1}=1 \mu \mathrm{H}$, then it steps down again from $50 \mathrm{~ns}$ to $20 \mathrm{~ns}$ at $L_{e 1}=8 \mu \mathrm{H}$. This double stepping-down in $T_{r}$ indicates that under $V_{1}<N \cdot V_{2} \& V_{r 2}=0$, if $L_{e l}$ is smaller than $1 \mu \mathrm{H}$ and dead time is set to be a value larger than $50 \mathrm{~ns}$ in order to achieve ZVS, $v_{a c 1}$ during dead time will have double wave crests and double wave troughs. These multi-resonances in the switching-node voltage of one of the FBs will cause distortions in the ac current, which flows in the other FB as well. As a result, the switching-node voltage of the other FB will be distorted. To conclude, prolonging the dead time does help realize ZVS even with small external inductance. However, this approach will cause distortions in the switching-node voltages and the ac current. 


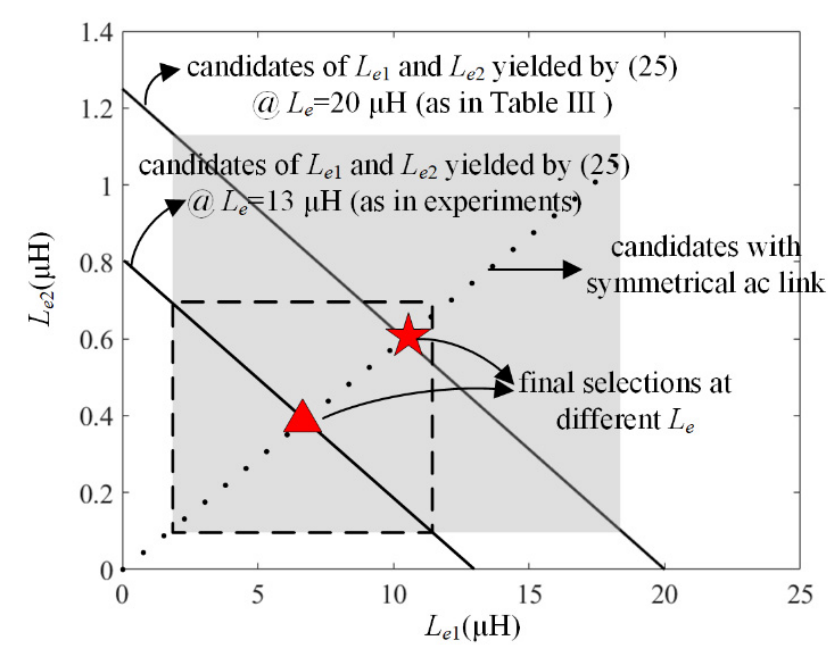

Fig. 11. Selection of the external inductance.

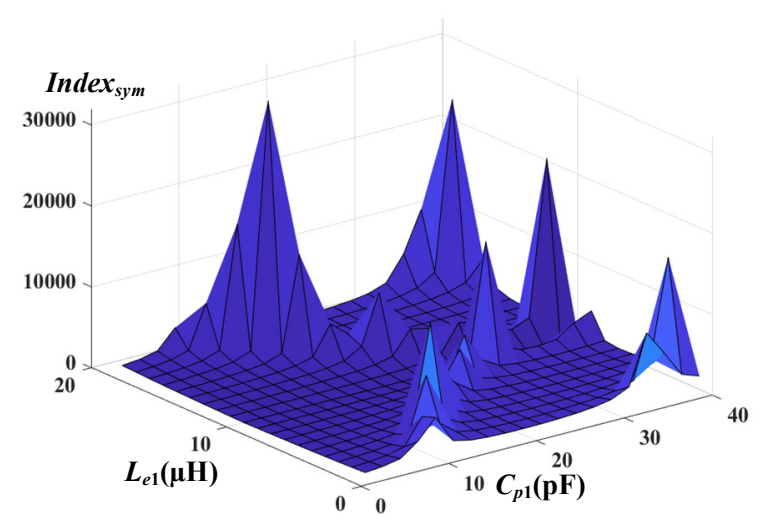

Fig. 12. Index $x_{s y m}$ vs. $L_{e 1} \& C_{p 1}$

Considering the DAB converter with SPSM, due to its symmetrical topology, the same conclusion can be applied to both of the FBs. Therefore, the external inductance needs to be placed on both sides of the transformer. By doing so the ZVS in both of the FBs can be achieved within a short dead time. This inductance assignment needs to ensure that the external inductances on both sides are larger than the calculated minimum values, with which $v_{a c 1}$ and $v_{a c 2}$ during dead time are quasi-sinusoidal, respectively. As shown in Figs. 7 and 8, the minimum values of the required external inductances are affected by the transformer parasitic capacitance, the relationship between $V_{1}$ and $N V_{2}$, and the modulation strategy.

\section{Selection of External Inductance}

Without considering ZVS performance, the constraint conditions of the external inductance $L_{e 1}$ and $L_{e 2}$ are:

$$
\left\{\begin{array}{c}
L_{e 1} \geq 0 \\
L_{e 2} \geq 0 \\
L_{e 1}+N^{2} L_{e 2}=L_{e}
\end{array}\right.
$$

Plot (25) and yield the solid lines in Fig. 11, where the selection of external inductance is visualized.

With achieving ZVS as one of the criteria, the dead time $T_{d}$ need to be determined at first. Using (19), in the SPSM controlled DAB converter with the parameters in Table III, the rising time of $v_{a c 1}$ will be shortened from 20 ns to $5 \mathrm{~ns}$ approximately once $L_{e 1}$ exceeds $2 \mu \mathrm{H}$, and the rising time of $v_{a c 2}$ will also be shortened from 20 ns to 6 ns approximately once $L_{e 2}$ exceeds $100 \mathrm{nH}$. When $T_{d}$ is selected to be $6 \mathrm{~ns}$, in order to achieve ZVS, $L_{e 1}$ can be any value between $2 \mu \mathrm{H}$ and $18.4 \mu \mathrm{H}$ (at $L_{e 1}=18.4 \mu \mathrm{H}, L_{e 2}$ reaches $100 \mathrm{nH}$ ), $L_{e 2}$ can be any value between $100 \mathrm{nH}$ and $1.125 \mu \mathrm{H}$ (at $L_{e 2}=1.125 \mu \mathrm{H}, L_{e 1}$ reaches 2 $\mu \mathrm{H})$. The candidates of $L_{e 1}$ and $L_{e 2}$ for realizing ZVS under $T_{d}$ of $6 \mathrm{~ns}$ are visualized as the grey area in Fig. 11.

In order to specify the inductances of the two external inductors, at least one criteria in addition to achieving ZVS is needed. The additional criteria used in this manuscript is to keep the ac link of the DAB converter as symmetrical as possible. As introduced in Section I, one of the attracting feature of the DAB converter is its symmetrical structure, which makes the DAB converter a promising topology for applications requiring bidirectional power flow. In bidirectional converters, the index of performance, e.g. efficiency, temperature rise of critical components, noises, at one direction of power flow is desired to be the same to those at the other direction. A detailed modeling of the effects of selecting the external inductances on the mismatch of index of performance is difficult. The degree of symmetry of the ac link can be estimated by calculating its input impedance in both directions of power flow. When power flows from $v_{a c 1}$ to $v_{a c 2}$, the input impedance of the ac link $Z_{\text {in_ } \_ \text {_ } 12}$ can be calculated as,

where

$$
Z_{\text {in_ac } \_12}=j \omega L_{e 1}+\frac{j \omega\left(N^{2} L_{e 2}+L_{k}\right)-j \omega^{3} L_{e 2} C_{p 2} L_{k}}{\text { Denom }_{12}}
$$

$$
\begin{gathered}
\text { Denom }_{12}=1-\omega^{2} L_{e 2} N^{2} C_{p}+L_{k} \omega^{2} C_{p 1}\left(\omega^{2} L_{e 2} C_{p 2}-1\right) \\
C_{p}=C_{p 1}+\frac{C_{p 2}}{N^{2}}
\end{gathered}
$$

On the other hand, when power flows from $v_{a c 2}$ to $v_{a c 1}$, the input impedance of the ac link $Z_{\text {in_ac_21 }}$ can be calculated as,

where

$$
Z_{\text {in_ac } \_21}=j \omega L_{e 2}+\frac{\frac{1}{N^{2}}\left[j \omega\left(L_{e 1}+L_{k}\right)-j \omega^{3} L_{e 1} C_{p_{1}} L_{k}\right]}{\operatorname{Denom}_{21}}
$$

$$
\text { Denom }_{21}=1-\omega^{2} L_{e 1} C_{p}+L_{k} \omega^{2} \frac{C_{p 2}}{N^{2}}\left(\omega^{2} L_{e 1} C_{p 1}-1\right)
$$

The mismatch between $Z_{\text {in_ac_12 }}$ and $Z_{\text {in_ac_21 }}$ is defined as:

$$
\delta Z_{\text {in_ac }}=Z_{\text {in_ac_12 }}-N^{\overline{2}} Z_{\text {in_ac_21 }}
$$

Substituting (26) and (29) into (31), $\delta Z_{\text {in_ac }}$ can be expressed as,

$$
\delta Z_{\text {in_ac }}=j \omega \delta L_{e}+\frac{k_{L_{e}} \delta L_{e}+k_{C p} \delta C_{p}+k_{C L} \delta_{C L}+k_{C C L} \delta_{C C L}}{\text { Denom }_{12} \text { Denom }_{21}}
$$

where Denom $_{12}$, Denom $_{21}, k_{L e}, \delta L_{e}, k_{C p}, \delta C_{p}, k_{C L}, \delta_{C L}, k_{C C L}$ and $\delta_{C C L}$ is defined as

$$
\begin{gathered}
k_{L_{e}}=-j \omega-j \omega^{3} L_{k} C_{p}+\frac{j \omega^{5} L_{k}^{2} C_{p 1} C_{p 2}}{N^{2}} \\
\delta L_{e}=L_{e 1}-N^{2} L_{e 2} \\
k_{C_{p}}=j \omega^{3} L_{k}^{2}-j \omega^{5} N^{2} L_{e 1} L_{e 2} L_{k} C_{p}+j \omega^{7} L_{e 1} L_{e 2} C_{p 1} C_{p 2} L_{k}^{2} \\
\delta C_{p}=C_{p 1}-\frac{C_{p 2}}{N^{2}} \\
k_{C L}=j \omega^{3} L_{k} \\
\delta_{C L}=L_{e 1} C_{p 1}-L_{e 2} C_{p 2} \\
k_{C C L}=-j \omega^{5} L_{k}^{2} \\
\delta_{C C L}=L_{e 1} C_{p 1} C_{p 1}-L_{e 2} C_{p 2} \frac{C_{p 2}}{N^{2}}
\end{gathered}
$$


The index of symmetry Index $x_{\text {sym }}$, which is defined in (41), is used to estimate the influences of $\delta Z_{\text {in ac }}$ on the degree of symmetry of bidirectional power flow in the DAB converter with SPSM.

$$
\text { Inde }_{\text {sym }}=\left.\sum_{n=1,3,5 \ldots} \frac{1}{n}\left|\delta Z_{\text {in_ac }}\right|\right|_{\omega=2 n \pi f_{s}}
$$

$n$ is defined as odd integers because that, ideally, in the DAB converter with SPSM, voltage and current flowing through the ac link are composed by the fundamental component and the odd order harmonics [26].

As expressed in (32), there are several contributors, i.e. $\delta L_{e}$, $\delta C_{p}, \delta_{C L}$, and $\delta_{C C L}$, to $\delta Z_{\text {in_ac }}$. Therefore, in order to minimize Index $_{\text {sym }}$, the selection of external inductances depends on the extent to which $C_{p 1}$ deviates from $C_{p 2} / N^{2}$.

Fig. 12 plots Index $x_{s y m}$ under varying $L_{e 1}$ and $C_{p 1}$ (Index Inym $_{\text {is }}$ calculated by up to $7^{\text {th }}$ order of odd harmonics). Note that when $C_{p 1}$ is $18 \mathrm{pF}$ as in Table III, $\delta C_{p}$ is $0.2 \mathrm{pF}$, which is only $1 \%$ of $C_{p 1}$. As shown, with the parameters in Table III, which is extracted from the transformer used in the experiments, Index sym $_{\text {. }}$ is minimized when $\delta L_{e}$ reaches zero. Therefore, with the objective of keeping the ac link as symmetrical as possible, the external inductances should be selected so that $L_{e 1}$ is equal to $N^{2} L_{e 2}$. This constraint yields the dot line in Fig. 11. Resultantly, as shown in Fig. 11, the star, which is the crossing of the dot line and the top solid line, are the final selections of the external inductances when $L_{e}=20 \mu \mathrm{H}$. Since the star is inside of the grey area, this final selection will guarantee the ZVS of all of the switches.

In the experiments, the total high-voltage-side referred inductance is $13 \mu \mathrm{H}$. With this inductance the converter works at rated power of $250 \mathrm{~W}$. The ZVS area with $L_{e}=13 \mu \mathrm{H} \& T_{d}=6$ ns is shown as the grey area bounded by dashed lines in Fig. 11. Analysis on Index $x_{\text {sym }}$ indicates that Index $x_{\text {sym }}$ is minimized when $\delta L_{e}$ reaches zero. Therefore, the final selection of external inductance is the triangle as marked in Fig. 11. The total highvoltage-side referred inductance is kept approximately the same for the three setups, i.e. $13.2 \mu \mathrm{H}$ in the single-high-voltage-side configuration, $12.6 \mu \mathrm{H}$ in the single-low-voltage-side configuration and $12.3 \mu \mathrm{H}$ in the configuration with two external inductors. In the configuration with two external inductors, the high-voltage-side-referred $L_{e 2}$ is $5.4 \mu \mathrm{H}, L_{e 1}$ is $6.9 \mu \mathrm{H}$. Note that considering the approximate $70-90 \mathrm{nH}$ inductance of the PCB traces in the ac link on the low voltage side, the high-voltageside-referred ac inductance on the low voltage side is $6.5-6.8 \mu \mathrm{H}$, which is close to $L_{e 1}$.

\section{EXPERIMENTS}

A $1 \mathrm{MHz}$ DAB converter prototype is built with the specifications listed in Table $\mathrm{V}$ to verify the theoretical analysis. The photos of the constructed prototype and the corresponding test setup are given in Fig. 13. In Fig. 13 (b), the transformer and inductors, which have been shown in Fig. 13(a), are removed in order to show the items of the prototype under the magnetic components. The parameters extracted from the prototype are given in Table III. $v_{a c 1}$ and $v_{a c 2}$ are measured by differential probes with bandwidth (BW) of $25 \mathrm{MHz}$, which is too low to monitor those multiple resonances in $v_{a c 1}$ and $v_{a c 2}$. Therefore, the multiple resonances are monitored by measuring the drain- source voltage $\left(v_{d s}\right)$ of the switches. $v_{d s}$ is measured by Lecroy PPE4kV with $6 \mathrm{pF}$ capacitance and BW of $400 \mathrm{MHz} . i_{L e 1}$ and $i_{L e 2}$ are measured by Lecroy CP030 and HIOKI3273-50current probes, which have the same $\mathrm{BW}$ of $50 \mathrm{MHz}$, respectively. In the following waveforms, $v_{d s}$ of EPC2016C is measured from Drain-to-Source of $S_{6}$, and $v_{d s}$ of GS66502B is measured from Drain-to-Source of $S_{4}$. N4L PPA5530 power analyzer measures

TABLE V. SPECIFICATIONS OF THE DAB PROTOTYPE

\begin{tabular}{|c|c|c|}
\hline & Description & Parameter \\
\hline \multirow{3}{*}{$\begin{array}{c}\text { Specifications } \\
\text { of the prototype }\end{array}$} & Switching Frequency & $1 \mathrm{MHz}$ \\
\cline { 2 - 3 } & DC voltage on the HV side & $200 \mathrm{Vdc}$ \\
\cline { 2 - 3 } & DC voltage on the LV side & $50 \mathrm{Vdc}$ \\
\cline { 2 - 3 } & Rated output power & $250 \mathrm{~W}$ \\
\hline \multirow{2}{*}{$\begin{array}{c}\text { Power } \\
\text { semiconductor }\end{array}$} & Switches on the HV side & GS66502B \\
\cline { 2 - 3 } Transformer & Switches on the LV side & EPC2016C \\
\hline \multirow{2}{*}{ Core's material, type, size } & $\begin{array}{c}\text { Hitachi Metals, } \\
\text { aL91S, } 2 \times \text { EE- } \\
\text { and turns ratio }\end{array}$ \\
\hline & HV side \& LV side & $21.8-11.4-15.8,8: 2$ \\
\hline
\end{tabular}

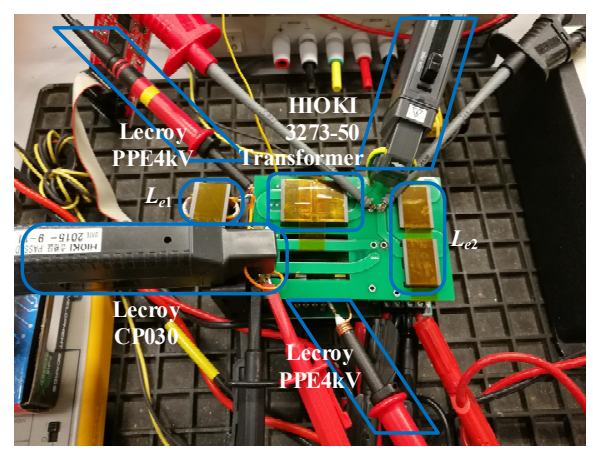

(a) Test setup

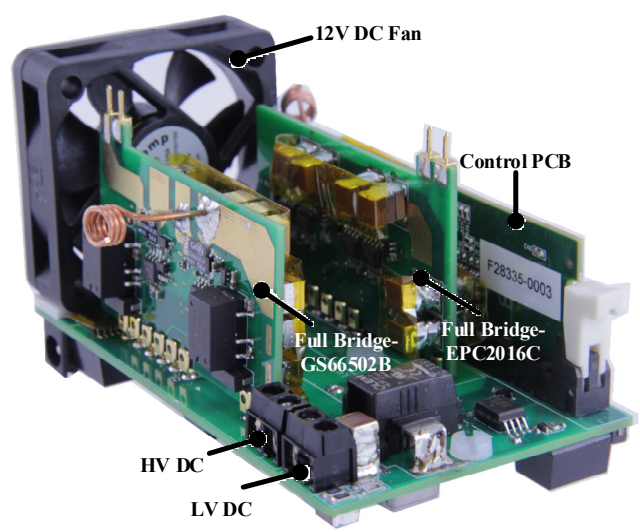

(b) Detailed view of the prototype

Fig. 13. Pictures of the hardware.

the input \& output voltage, the input \& output power, and the efficiency without any probes connected.

The verification of analysis on Switching-Pattern \#1 and \#2 are given in Subsection-A and -B, respectively. No experiments are performed to investigate Switching-Pattern \#3 and \#4 because hard switching always comes along with these two patterns. The efficiency measurements are given in Subsection$\mathrm{C}$ to show that splitting the external inductances is able to improve the efficiency. Finally, all the experimental results are summarized in Subsection-D. 


\section{A. Experiments on the DAB converter with SPSM}

First, place an external inductor of $13.2 \mu \mathrm{H}$ on the high voltage side (HVs); directly connect the low voltage side (LVs) FB to the transformer and no external inductance in between. The LVs ac current is not measured in such setup to minimize the external inductance on the LVs. This external inductance configuration will ease ZVS realization of the HVs because the external inductance of $13.2 \mu \mathrm{H}$ is larger than the required minimum inductance of $2 \mu \mathrm{H}$; however, deteriorate the ZVS on the LVs. As in the measured experimental waveforms shown in Fig.12, GaN transistors GS66502B have soft switching, however, EPC2016C is partial hard switching due to the long rising time of its $v_{d s}$. The waveforms of the rising and the falling of $v_{d s}$ of EPC2016C are not symmetrical. The first wave crest during rising is larger than $V_{2}$, in converse, the first trough during falling is larger than 0 . This is caused by the dc offset in $i_{L e 2}$, which leads to different initial currents for the high-side-to-lowside and low-side-to-high-side commutations. In spite of the asymmetry, the measured time duration for $v_{d s}$ of $S_{6}$ to rise from 0 to $V_{2}$ after the first wave trough is $20 \mathrm{~ns}$ and match the calculations. So does the measured time duration for $v_{d s}$ of $S_{6}$ to fall from $V_{2}$ to 0 after the first wave crest. However, the rising time of $v_{d s}$ of GS66502B is $21 \mathrm{~ns}$, which is different from the calculated 5ns. This mismatching in GS66502B is caused by the input capacitance of the probe and the parasitic capacitance of the PCB traces, which is around $25 \mathrm{pF}$. These two together contribute an additional capacitance of around $31 \mathrm{pF}$ in parallel to the output capacitance of GS66502B, which is $17 \mathrm{pF}$. Without consideration of the parasitic capacitances of the transformer, the total capacitance of $48 \mathrm{pF}$ will lead to a rising time of around $15 \mathrm{~ns}$ according to the equations in [7]. Because the output capacitance of EPC2016C is $310 \mathrm{pF}$, which is much larger than the input capacitance of the probe and the parasitic capacitance of the PCB traces, the calculated rising time of EPC2016C is thereby close to the measured one. Therefore, the validity of the derived model in Section II is verified.

Second, the external inductance of $787 \mathrm{nH}$ is placed on the LVs and directly connect the FB on the HVs to the transformer. This configuration will ease ZVS realization on the LVs because the external inductance of $787 \mathrm{nH}$ is larger than the required minimum inductance of $100 \mathrm{nH}$, and on the other hand, it will deteriorate the ZVS on the HVs. As the waveforms shown in Fig.13, EPC2016C has soft switching; however, GS66502B is partial hard switching. Comparing the measured rising time to the calculated one, $v_{d s}$ rising time of EPC2016C is $5 \mathrm{ns,} \mathrm{which}$ matches the calculation. For GS66502B, partial hard switching occurs when the external inductor is located on the LVs. Under the same dead time of $25 \mathrm{~ns}$, GS66502B achieves ZVS when the external inductor is located on the HVs. Therefore, the influences on the ZVS due to the transformer parasitic capacitances, which have been analyzed in Section IV-A, are verified.

Finally, the external inductors of $6.9 \mu \mathrm{H}$ and $336 \mathrm{nH}$ are added and placed on both the HVs and LVs, respectively. Based on the analysis, this configuration will ease ZVS realization of both the FBs since the external inductance on both sides of the transformer are larger than the required minimum ones. The corresponding experimental waveforms are given in Fig. 16. As shown in these waveforms, both GS66502B and EPC2016C are able to achieve ZVS. Therefore, the proposed solution to mitigate the effects of the transformer parasitic capacitances on ZVS, i.e. assigning the external inductance to ensure the
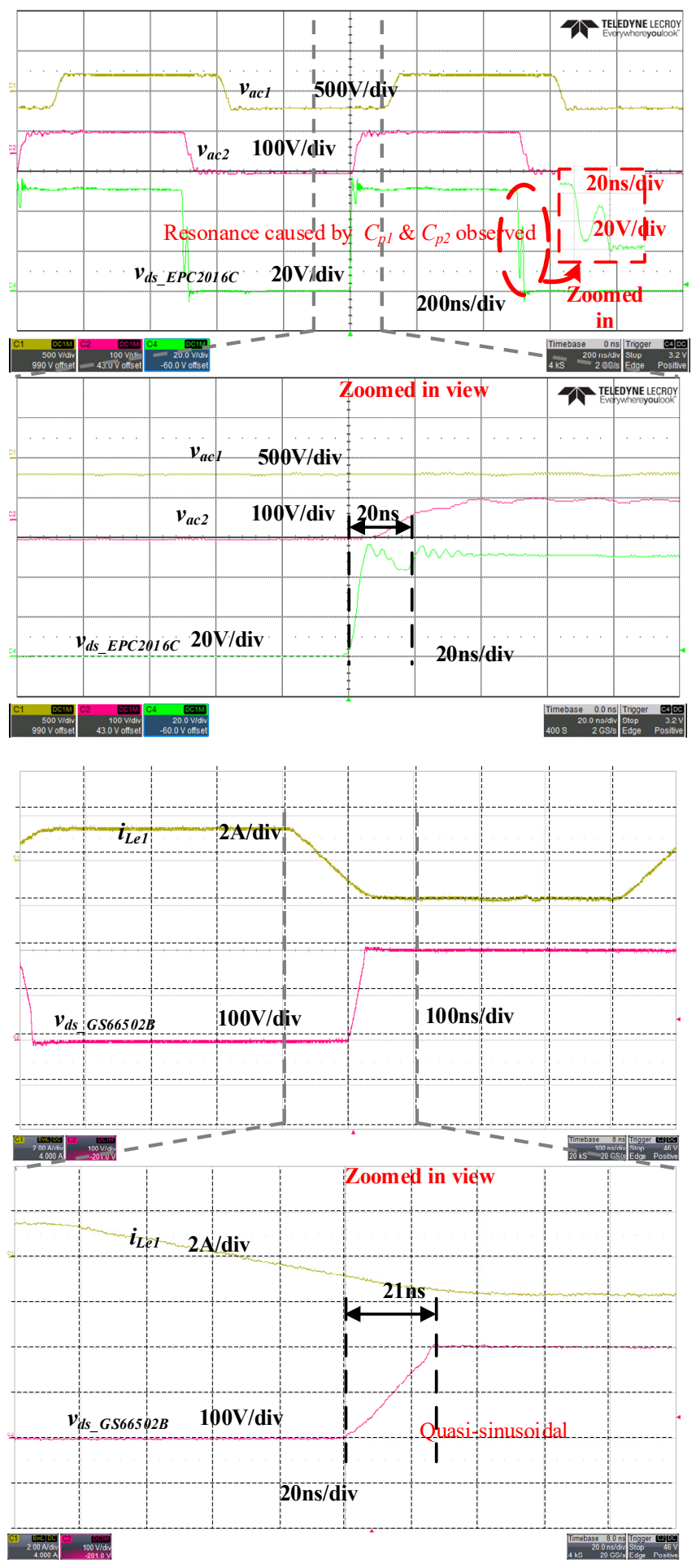

Fig. 14. Measurements of the DAB converter with SPSM and HVs-located external inductance. 


\section{IEEE POWER ELECTRONICS REGULAR PAPER/LETTER/CORRESPONDENCE}

minimum needed inductance on both sides of the transformer, is verified on the DAB converter with SPSM.

\section{B. Experiments on the DAB converter with TPSM}

The following experiments are implemented on the same DAB prototype with TPSM to investigate the impacts of ac inductor placement on Switching-Pattern \#2. The test procedure

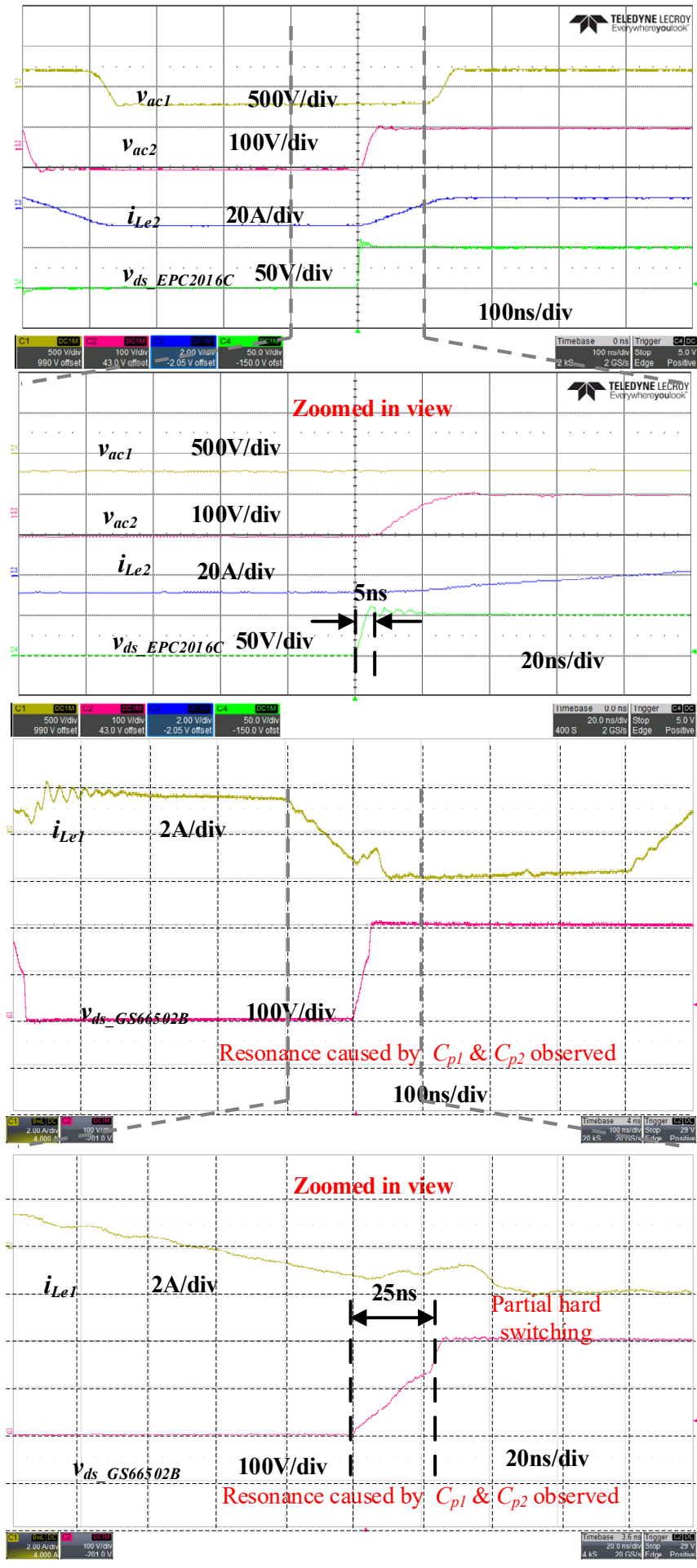

Fig. 15. Measurements of the DAB converter with SPSM and LVs-located external inductance. is the same as that presented in the Sub-section A. First, place an external inductance of $787 \mathrm{nH}$ on the LVs and directly connect the FB on the HVs to the transformer. The measured waveforms are given in Fig. 17. As shown, this configuration eases ZVS realization on the LVs, and deteriorates the ZVS on the HVs. Both of the FBs achieve ZVS when the external inductances are

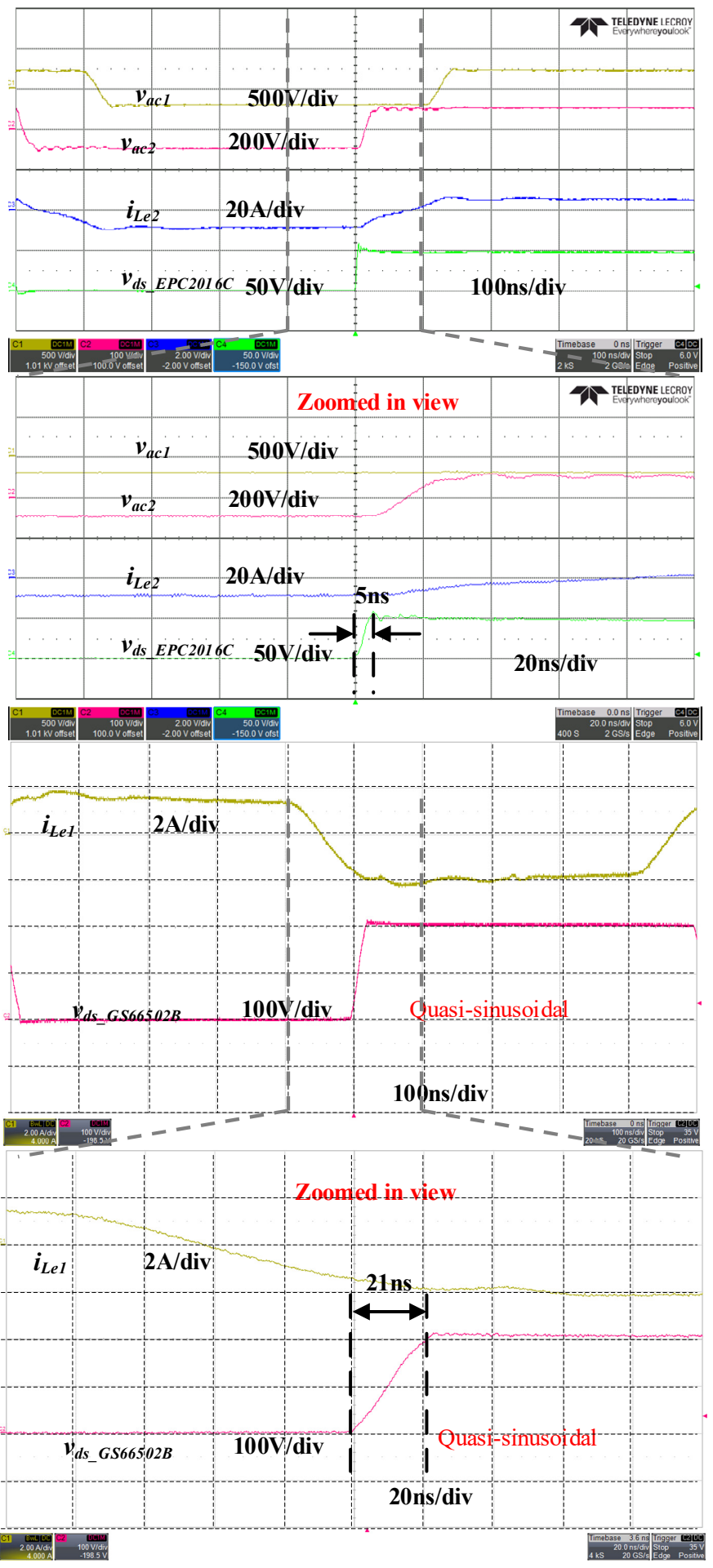

Fig. 16. Measurements the DAB converter with SPSM and split external inductance. 


\section{IEEE POWER ELECTRONICS REGULAR PAPER/LETTER/CORRESPONDENCE}

placed on both the HVs and LVs by adding the external inductors of $6.9 \mu \mathrm{H}$ and $336 \mathrm{nH}$, respectively. The measured waveforms are given in Fig. 18. As shown, both GS66502B and EPC2016C achieve ZVS. Therefore, the proposed solution to mitigate the effects of the transformer's parasitic capacitances on ZVS, i.e. assigning the external inductance to ensure the

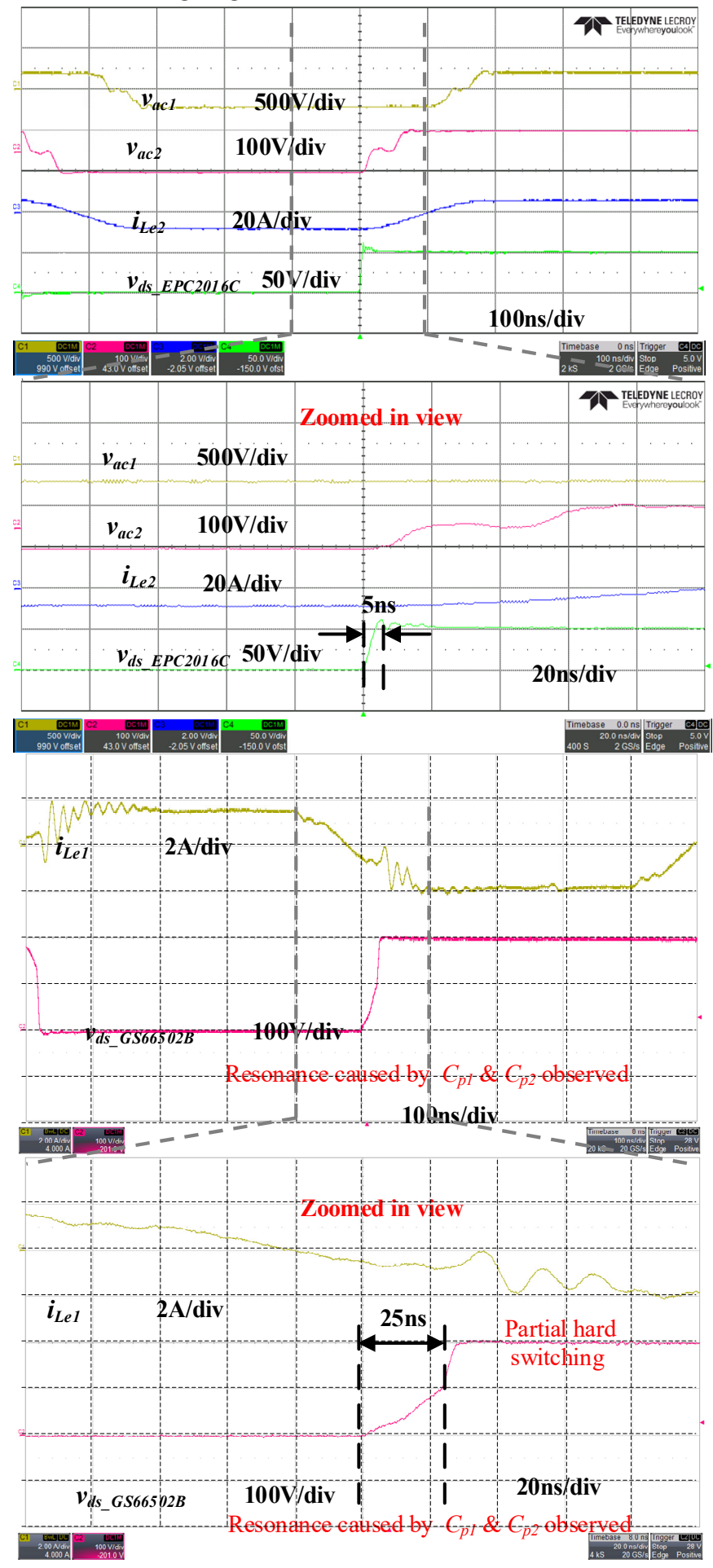

Fig. 17. Measurements of the DAB converter with TPSM and LVs-located external inductance. minimum needed inductance on both sides of the transformer, is valid and verified on the DAB converter with TPSM.

\section{Power and efficiency measurements}

The input power, the output power and the efficiency of the prototype under the test conditions stated above are listed in Table VI, where 'SPSM-H' means SPSM with external inductor
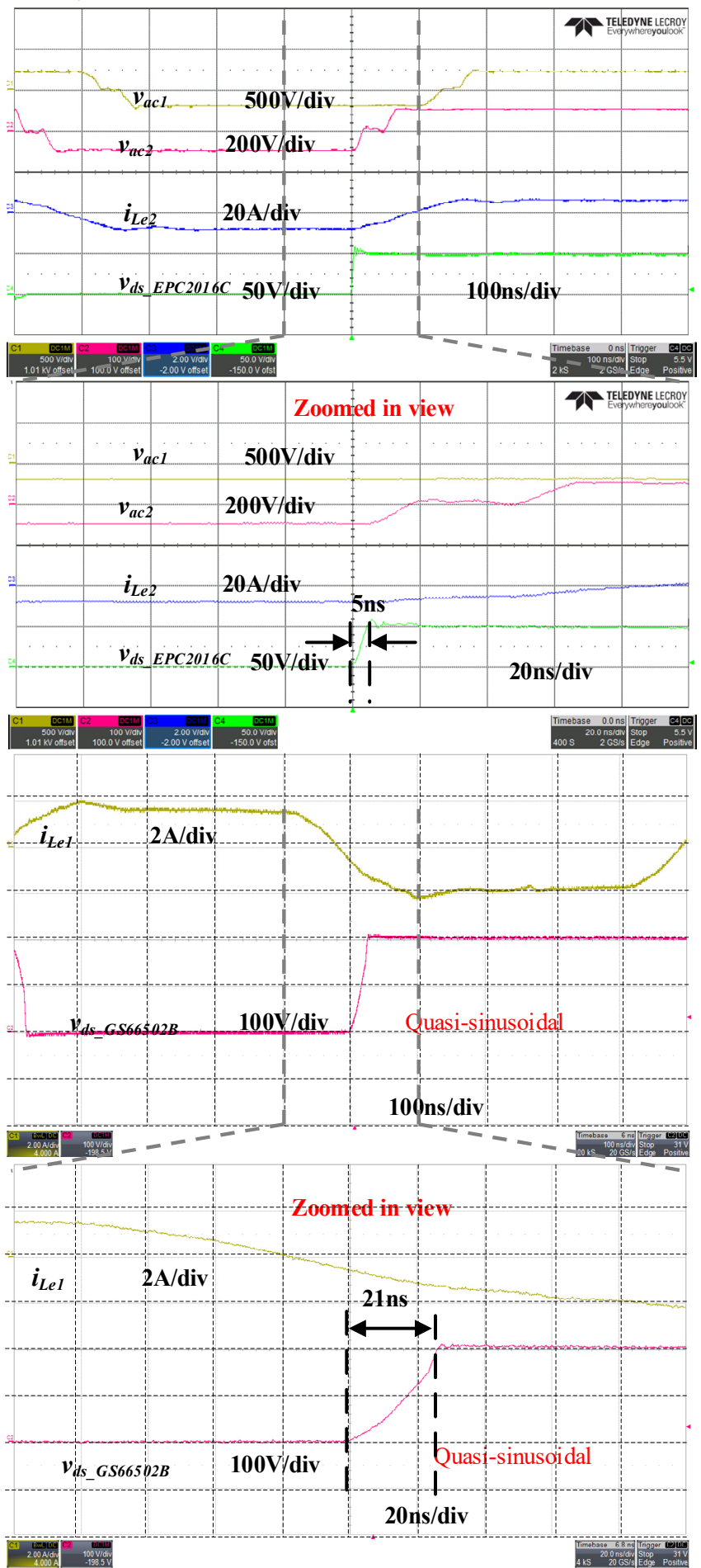

Fig. 18. Measurements the DAB converter with TPSM and split external inductance. 
TABLE VI. POWER AND EFFICIENCY MEASUREMENTS WITHOUT ANY PROBES ATTACHED

\begin{tabular}{|c|c|c|c|c|c|}
\hline & SPSM-H & SPSM-L & $\begin{array}{c}\text { SPSM- } \\
\text { HL }\end{array}$ & TPSM-L & $\begin{array}{c}\text { TPSM- } \\
\text { HL }\end{array}$ \\
\hline$V_{1}(\mathrm{~V})$ & 200 & 201 & 201 & 200 & 201 \\
\hline$V_{2}(\mathrm{~V})$ & 51.0 & 51.7 & 49.0 & 52.8 & 49.7 \\
\hline$\phi_{P-S}$ & $-6 \pi / 25$ & $-6 \pi / 25$ & $-6 \pi / 25$ & $-6 \pi / 25$ & $-6 \pi / 25$ \\
\hline$\phi_{P}$ & & & & $2 \pi / 25$ & $2 \pi / 25$ \\
\hline$\phi_{S}$ & 245 & 265 & 266 & 263 & 264 \\
\hline $\begin{array}{c}\text { Input } \\
\text { Power } \\
\text { (W) }\end{array}$ & 229 & 250 & 250 & 247 & 251 \\
\hline $\begin{array}{c}\text { Output } \\
\text { Power } \\
\text { (W) }\end{array}$ & 93.6 & 94.6 & 94.0 & 94.2 & 95.0 \\
\hline $\begin{array}{c}\text { Efficiency } \\
(\%)\end{array}$ & & & & $2 \pi / 25$ & $2 \pi / 25$ \\
\hline
\end{tabular}

TABLE VII. Summary of THERMAL BeHAVIOR of THE Prototype UNDER 'SPSM-L' AND 'SPSM-HL'

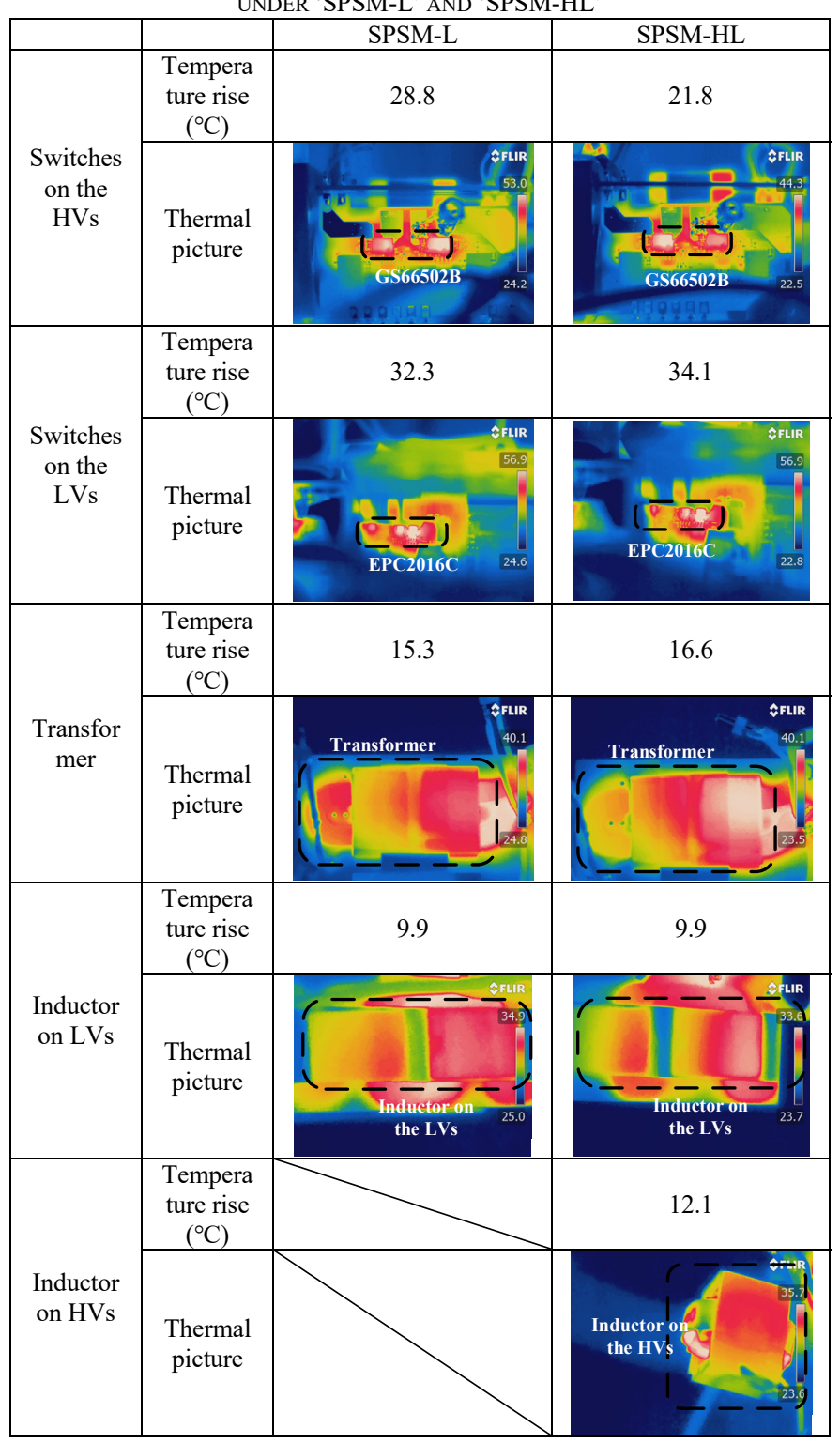

on the HVs, naming of other columns in the header row follows this naming rule, which is 'modulation strategy'-'location of the external inductor'. From Table VI, we can see the possibility of increasing the prototype's efficiency by splitting the external inductance on both sides of the transformer is verified on the prototype modulating by TPSM. Under the same input/output power, the same phase shift angle, and the same input/output voltage, the efficiency is increased by $0.8 \%$ by splitting the external inductance.

As shown, the efficiency under 'SPSM-HL' is lower than that under 'SPSM-L', which means achieving ZVS of all of the switches in the tested DAB converter with SPSM does not necessarily increase the efficiency of the prototype. This observation is worthy of investigation since it indicates that either achieving ZVS does not necessarily brings down the losses of switches or splitting the external inductors on both of the two sides of transformer increases losses of components other than switches.

In order to investigate the loss distribution, thermal measurement is implemented to illustrate the loss changes caused by different placement of inductors. T650sc from FLIR is used to monitor the temperature of individual components of the prototype under 'SPSM-L' and 'SPSM-HL'. The thermal measurements are summarized in Table VII. As illustrated in the rows titled with 'Switches on the HVs', the temperature rise of the switches on the HVs under 'SPSM-HL' is $7^{\circ} \mathrm{C}$ lower or $25 \%$ smaller than that under 'SPSM-L'. It indicates that the losses of the switches on the HVs do decrease when the external inductor is split and placed on two sides of the transformer. The temperature rise of the switches on the LVs increases $1.8{ }^{\circ} \mathrm{C}$ in 'SPSM-HL' compared to 'SPSM-L'. Given the same heat dissipation conditions in the experimental setup (the total area of copper used to dissipate heat from GS66502B is the same to that of EPC2016C) and the same junction-to-case thermal resistance of $2{ }^{\circ} \mathrm{C} / \mathrm{W}$ of GS66502B and EPC2016C, the decreased losses in GS66502B cannot be cancelled out by the increased losses in EPC2016C. Therefore, there are additional losses comes from components other than switches.

This hypothesis is proved by the thermal measurements of the transformer and the inductors, as it shows in the rows titled with 'Transformer', 'Inductor on LVs' and 'Inductor on HVs'. The temperature rise of the transformer increases $1.3^{\circ} \mathrm{C}$ in 'SPSMHL' compared to 'SPSM-L'. The loss of the inductor on the LVs remains unchanged in the two setups. The inductor on the HVs has a temperature rise of $12^{\circ} \mathrm{C}$.

Therefore, the efficiency drop of the prototype under 'SPSMHL' compared to 'SPSM-L' is mainly caused by the additional losses in the inductor on the high voltage side. This amount of additional loss is large enough to cancel out the amount of reduced losses of the soft-switched transistors on the HVs. The two external inductors need to be carefully designed to keep the inductors' losses as low as possible.

To conclude, compared to 'SPSM-L', all of the switches in the 'SPSM-HL' configuration achieve ZVS. However, the additional inductor on the high voltage side might increase the total loss of the converter. 
The external inductors used in this paper are designed to achieve ZVS and make the DAB converter symmetrical, as explained in Subsection-D of Section IV. Investigating the design guidelines on how to split the external inductors in order to fulfill other design criteria, e.g. minimize total loss of the converter, could be the topics for the future research.

In summary, it is found that placing inductance on both side of the high frequency transformer can effectively extend the ZVS for all the switching devices on both high voltage and low voltage sides. The converter thereby has less EMI issues. The possibility of boosting the DAB converter's efficiency by solely splitting the external inductance on both of the two sides of the transformer is verified experimentally. Notably, even though the SPSM-HL configuration has slightly lower efficiency than the SPSM-L configuration, GS66502B ZVS operation is ensured and thereby these GaN devices will have lower loss as well as low switching noises. In other words, the losses are moved from GS66502B to the external inductor on the high voltage side, which has a larger area for heat dissipation than GS66502B. Thus, GaN devices can operate more reliably because of less thermal stress.

\section{CONCLUSIONS}

This paper addressed the issue of ZVS operation affected by the transformer parasitic capacitance in high frequency DAB converters. A mathematical model, which considers the parasitic capacitances of the transformer, is derived to describe the resonant transition during the dead time. It is found that placing inductance on both side of the high frequency transformer can effectively extend the ZVS for all the switching devices on both high voltage and low voltage sides. A systematic design guideline of the external inductors with the objective of keeping the $\mathrm{DAB}$ converter symmetrical is provided. The proposed solution is verified by the measurement results from the constructed $1 \mathrm{MHz}$ GaN-based DAB prototype. In the future research work, inductor design optimization in terms of impedance matching and loss reduction need to be investigated further to improve efficiency under various modulation schemes.

\section{REFERENCES}

[1] R. W. A. A. De Doncker, D. M. Divan and M. H. Kheraluwala, "A threephase soft-switched high-power-density DC/DC converter for high-power applications," in IEEE Transactions on Industry Applications, vol. 27, no. 1, pp. 63-73, Jan.-Feb. 1991.

[2] M. N. Kheraluwala, R. W. Gascoigne, D. M. Divan and E. D. Baumann, "Performance characterization of a high-power dual active bridge DC-toDC converter," in IEEE Transactions on Industry Applications, vol. 28, no. 6, pp. 1294-1301, Nov.-Dec. 1992.

[3] B. Zhao, Q. Song, W. Liu and Y. Sun, "Overview of Dual-Active-Bridge Isolated Bidirectional DC-DC Converter for High-Frequency-Link Power-Conversion System," in IEEE Transactions on Power Electronics, vol. 29, no. 8, pp. 4s091-4106, Aug. 2014.

[4] F. Krismer and J. W. Kolar, "Accurate Power Loss Model Derivation of a High-Current Dual Active Bridge Converter for an Automotive Application," in IEEE Transactions on Industrial Electronics, vol. 57, no. 3, pp. 881-891, March 2010.

[5] J. Everts, F. Krismer, J. Van den Keybus, J. Driesen and J. W. Kolar, "Charge-based ZVS soft switching analysis of a single-stage dual active bridge AC-DC converter," 2013 IEEE Energy Conversion Congress and Exposition, Denver, CO, 2013, pp. 4820-4829.

[6] J. Everts, F. Krismer, J. Van den Keybus, J. Driesen and J. W. Kolar, "Optimal ZVS Modulation of Single-Phase Single-Stage Bidirectional DAB AC-DC Converters," in IEEE Transactions on Power Electronics, vol. 29, no. 8, pp. 3954-3970, Aug. 2014.

[7] D. Costinett, D. Maksimovic and R. Zane, "Design and Control for High Efficiency in High Step-Down Dual Active Bridge Converters Operating at High Switching Frequency," in IEEE Transactions on Power Electronics, vol. 28, no. 8, pp. 3931-3940, Aug. 2013.

[8] A. Rodríguez, A. Vázquez, D. G. Lamar, M. M. Hernando and J. Sebastián, "Different Purpose Design Strategies and Techniques to Improve the Performance of a Dual Active Bridge With Phase-Shift Control," in IEEE Transactions on Power Electronics, vol. 30, no. 2, pp. 790-804, Feb. 2015.

[9] Y. Wang, H. Song and D. Xu, "Soft-Switching Bidirectional DC/DC Converter With an LCLC Resonant Circuit," in IEEE Journal of Emerging and Selected Topics in Power Electronics, vol. 7, no. 2, pp. 851-864, Feb. 2019.

[10] Y. Wang, S. Gao and D. Xu, "A 1-MHz-Modified SEPIC With ZVS Characteristic and Low-Voltage Stress," IEEE Transactions on Industrial Electronics, vol. 66, no. 5, pp. 3422-3426, May. 2019.

[11] Y. Guan, Y. Wang, W. Wang and D. Xu, "A High-Performance Isolated High-Frequency Converter With Optimal Switch Impedance," IEEE Transactions on Industrial Electronics, vol. 66, no. 7, pp. 5165-5176, Jul. 2019.

[12] L. Xue, D. Boroyevich and P. Mattavelli, "Switching condition and loss modeling of GaN-based dual active bridge converter for PHEV charger," 2016 IEEE Applied Power Electronics Conference and Exposition (APEC), Long Beach, CA, 2016, pp. 1315-1322.

[13] D. Costinett, "Reduced order discrete time modeling of ZVS transition dynamics in the dual active bridge converter," 2015 IEEE Applied Power Electronics Conference and Exposition (APEC), Charlotte, NC, 2015, pp. 365-370.

[14] J. A. Santiago-González, D. M. Otten and D. J. Perreault, "Light Load Efficiency Improvements in Dual Active Bridge Converters via Dead time Control," 2018 IEEE 19th Workshop on Control and Modeling for Power Electronics (COMPEL), Padua, 2018, pp. 1-7.

[15] J. Riedel, D. G. Holmes, B. P. McGrath and C. Teixeira, "ZVS Soft Switching Boundaries for Dual Active Bridge DC-DC Converters Using Frequency Domain Analysis," in IEEE Transactions on Power Electronics, vol. 32, no. 4, pp. 3166-3179, April 2017.

[16] G. Oggier, G. O. García and A. R. Oliva, "Modulation strategy to operate the dual active bridge DC-DC converter under soft switching in the whole operating range," in IEEE Transactions on Power Electronics, vol. 26, no. 4, pp. 1228-1236, April 2011.

[17] M. Kim, M. Rosekeit, S. Sul and R. W. A. A. De Doncker, "A dual-phaseshift control strategy for dual-active-bridge DC-DC converter in wide voltage range," 8th International Conference on Power Electronics ECCE Asia, Jeju, 2011, pp. 364-371.

[18] F. Krismer and J. W. Kolar, "Closed Form Solution for Minimum Conduction Loss Modulation of DAB Converters," in IEEE Transactions on Power Electronics, vol. 27, no. 1, pp. 174-188, Jan. 2012.

[19] F. Krismer and J. W. Kolar, "Efficiency-Optimized High-Current Dual Active Bridge Converter for Automotive Applications," in IEEE Transactions on Industrial Electronics, vol. 59, no. 7, pp. 2745-2760, July 2012.

[20] A. Taylor, G. Liu, H. Bai, A. Brown, P. M. Johnson and M. McAmmond, "Multiple-Phase-Shift Control for a Dual Active Bridge to Secure ZeroVoltage Switching and Enhance Light-Load Performance," in IEEE Transactions on Power Electronics, vol. 33, no. 6, pp. 4584-4588, June 2018.

[21] Z. Qin, Z. Shen and F. Blaabjerg, "Modelling and analysis of the transformer current resonance in dual active bridge converters," 2017 IEEE Energy Conversion Congress and Exposition (ECCE), Cincinnati, OH, 2017, pp. 4520-4524.

[22] Y. Xie, J. Sun and J. S. Freudenberg, "Power Flow Characterization of a Bidirectional Galvanically Isolated High-Power DC/DC Converter Over 


\section{IEEE POWER ELECTRONICS REGULAR PAPER/LETTER/CORRESPONDENCE}

a wide Operating Range," in IEEE Transactions on Power Electronics, vol. 25, no. 1, pp. 54-66, Jan. 2010.

[23] B. Zhao, Q. Song, W. Liu and Y. Sun, "Dead-Time Effect of the HighFrequency Isolated Bidirectional Full-Bridge DC-DC Converter: Comprehensive Theoretical Analysis and Experimental Verification," in IEEE Transactions on Power Electronics, vol. 29, no. 4, pp. 16671680, April 2014.

[24] H. Bai, C. C. Mi and S. Gargies, "The Short-Time-Scale Transient Processes in High-Voltage and High-Power Isolated Bidirectional DCDC Converters," in IEEE Transactions on Power Electronics, vol. 23, no. 6, pp. 2648-2656, Nov. 2008.
[25] K. Shen et al., "ZVS Control strategy of dual active bridge DC/DC converter with triple-phase-shift modulation considering RMS current optimization," in The Journal of Engineering, vol. 2019, no. 18, pp. 47084712, 72019.

[26] Z.Zhang, O. C. Thomsen and M. A. E. Andersen, "Optimal design of a push-pull-forward half-bridge (PPFHB) bidirectional DC-DC converter with variable input voltage," in IEEE Transactions on Industrial Electronics, vol. 59, no. 7, pp. 2761-2771, Jul. 2012. 